Article

\title{
Volcanic Rock Materials for Defluoridation of Water in Fixed-Bed Column Systems
}

\author{
Wondwosen Sime Geleta ${ }^{1,2}(\mathbb{D})$, Esayas Alemayehu ${ }^{3,4, *}$ and Bernd Lennartz ${ }^{2, *(\mathbb{D})}$ \\ 1 School of Chemical Engineering, Jimma Institute of Technology, Jimma University, \\ P.O. Box 378, Jimma, Oromia, Ethiopia; wondeto@gmail.com \\ 2 Faculty of Agricultural and Environmental Sciences, University of Rostock, Justus-Von-Liebig-Weg 6, \\ 18059 Rostock, Germany \\ 3 Faculty of Civil and Environmental Engineering, Jimma Institute of Technology, Jimma University, \\ P.O. Box 378, Jimma, Oromia, Ethiopia \\ 4 Africa Center of Excellence for Water Management, Addis Ababa University, 1176 Addis Ababa, Ethiopia \\ * Correspondence: esayas16@yahoo.com (E.A.); bernd.lennartz@uni-rostock.de (B.L.); \\ Tel.: +251-91-701-7002 (E.A.); +49-381-498-3180 (B.L.)
}

check for

updates

Citation: Geleta, W.S.; Alemayehu, E.; Lennartz, B. Volcanic Rock Materials for Defluoridation of Water in Fixed-Bed Column Systems. Molecules 2021, 26, 977. https:// doi.org/10.3390/molecules26040977

Academic Editor: Giorgio Vilardi

Received: 7 December 2020

Accepted: 8 February 2021

Published: 12 February 2021

Publisher's Note: MDPI stays neutral with regard to jurisdictional claims in published maps and institutional affiliations.

Copyright: (c) 2021 by the authors. Licensee MDPI, Basel, Switzerland. This article is an open access article distributed under the terms and conditions of the Creative Commons Attribution (CC BY) license (https:// creativecommons.org/licenses/by/ $4.0 /)$.

\begin{abstract}
Consumption of drinking water with a high concentration of fluoride $(>1.5 \mathrm{mg} / \mathrm{L})$ causes detrimental health problems and is a challenging issue in various regions around the globe. In this study, a continuous fixed-bed column adsorption system was employed for defluoridation of water using volcanic rocks, virgin pumice (VPum) and virgin scoria (VSco), as adsorbents. The XRD, SEM, FTIR, BET, XRF, ICP-OES, and pH Point of Zero Charges $\left(\mathrm{pH}_{\mathrm{PZC}}\right)$ analysis were performed for both adsorbents to elucidate the adsorption mechanisms and the suitability for fluoride removal. The effects of particle size of adsorbents, solution $\mathrm{pH}$, and flow rate on the adsorption performance of the column were assessed at room temperature, constant initial concentration, and bed depth. The maximum removal capacity of $110 \mathrm{mg} / \mathrm{kg}$ for VPum and $22 \mathrm{mg} / \mathrm{kg}$ for VSco were achieved at particle sizes of $0.075-0.425 \mathrm{~mm}$ and $<0.075 \mathrm{~mm}$, respectively, at a low solution $\mathrm{pH}(2.00)$ and flow rate $(1.25 \mathrm{~mL} / \mathrm{min})$. The fluoride breakthrough occurred late and the treated water volume was higher at a low $\mathrm{pH}$ and flow rate for both adsorbents. The Thomas and Adams-Bohart models were utilized and fitted well with the experimental kinetic data and the entire breakthrough curves for both adsorbents. Overall, the results revealed that the developed column is effective in handling water containing excess fluoride. Additional testing of the adsorbents including regeneration options is, however, required to confirm that the defluoridation of groundwater employing volcanic rocks is a safe and sustainable method.
\end{abstract}

Keywords: adsorption; breakthrough curve; defluoridation; up-flow mode; volcanic rocks

\section{Introduction}

Credible evidence from scientific literature substantiates both beneficial and detrimental effects of fluoride on human health with only a narrow range between intake associated with these effects [1,2]. Consumptions of fluoride in low concentrations $(<1.0 \mathrm{mg} / \mathrm{L})$ is an essential micronutrient for the healthy development of bone and dental enamel [3]; however, it leads to the development of fluorosis if it is consumed beyond the permissible limit (>1.5 mg/L) [4].

In many parts of the world, groundwater sources are the single largest supply of drinking water. For many rift communities, it may be the only economically viable option for drinking water. In the Ethiopian rift valley, about $40 \%$ of deep and shallow wells are contaminated with up to $26 \mathrm{mg} / \mathrm{L}$ of fluoride $[5,6]$. The weathering of primary rocks and leaching of fluoride-containing minerals in soils yield fluoride-rich groundwater in the Ethiopian Rift, which is generally associated with a low calcium content and high bicarbonate concentrations $[7,8]$. 
Globally, more than 200 million people, including Ethiopia, rely on groundwater with a fluoride concentration above the permissible level [3,4,9]. According to the Central Statistical Agency of Ethiopia report [10], 3.8\% of the population is affected by high-level fluoride concentrations $(>1.5 \mathrm{mg} / \mathrm{L})$ in groundwater, which is used for drinking purposes. In general, fluorosis turns out to be the most widespread geochemical-based disease in the East African rift, affecting more than 80 million people [11-14]. Thus, due to the health effect of high fluoride in groundwater, it is essential to reduce excess fluoride concentrations to the allowable limit $(<1.5 \mathrm{mg} / \mathrm{L})$.

So far, various technologies such as coagulation/precipitation, electro-coagulation, membrane separations, ion exchange, and adsorption had been attempted for efficient defluoridation of groundwater [15-18]. Some of the shortfalls of these techniques include expensiveness, fouling issues, regular maintenance, and complicated operational procedures. In comparison to the techniques mentioned above, the adsorption methodology is still one of the most widely applied methods, taking the lead of high removal efficiency, cost-effectiveness, ease of operation, simplicity of design, and availability of large varieties of adsorbents $[19,20]$.

Various adsorbents have been investigated and reported for the removal of excess fluoride from water in an effective manner. Some of the widely employed adsorbents are La (III)-Al (III)-activated carbon modified by chemical route [21], biomaterial functionalized cerium nanocomposite [22], Quaternized Palm Kernel Shell (QPKS) [23], bone char and activated alumina [24], bone char [25], renewable biowaste [26], $\mathrm{MgFe}_{2} \mathrm{O}_{4}$-chitosan-CaAl nanohybrid [27], carbon nanotube composite [15], Neem Oil-Phenolic Resin Treated Biosorbent [17], etc. However, many of these suffer from either time-consuming synthesis procedure, high processing costs, availability of raw materials, or short lifespan, which makes them impractical to be applied in the rift valleys that are essentially impacted by high fluoride concentration in water [1]. Consequently, efforts have been made to obtain easily accessible and long-lasting, low-cost, and efficient adsorbents that may be applied for the purification of water in low-income countries such as Ethiopia.

In recent years, volcanic rocks (VPum and VSco) have received significant interest for pollutant removal due to their valuable properties such as high surface area, low-cost, easy accessibility, good mechanical resistance, and availability in large quantities [28]. The source of these rocks is volcanic magma that formed during volcanic eruptions. Pumice (VPum) is a finely porous rock frothy with air bubbles; Scoria (VSco) is a rough rock that seems like furnace slag [28]. VPum is often formed from rhyolite magma [28], it can also develop from trachytic or dacitic magma. Due to its high porosity and low specific gravity, it has been used for water and wastewater treatment processes [29]. VSco is a vesicular pyroclastic rock with basaltic compositions, reddish-brown to black, denser than VPum, somewhat porous with high surface area and strength. Both volcanic rocks are found in abundance in Europe (Italy, etc.), Central America, Southeast Asia (Indonesia, etc.), and East Africa (Ethiopia, Eritrea, etc.) [28,29]. Although several studies have been conducted on the application of volcanic rocks for pollutants-laden wastewaters [28-31], very little research has been directed to the defluoridation of groundwater using volcanic rocks.

Previously, defluoridation research has been conducted on batch experiments using natural adsorbents [6,32]. The sorption capacity of adsorbents gained from batch equilibrium is valuable in giving basic information about the effectiveness of the adsorbents. Nevertheless, the data obtained from batch studies may not be appropriate for continuous processes where the contact time for the achievement of an equilibrium might be insufficient [33]. Consequently, studies by different authors [34-36] reveal that continuous processes mode (fixed-bed column set-up) yields reliable information about the breakthrough time, appropriate adsorption conditions, and the stability of the adsorption performance which can then be used to evaluate the potential of prepared adsorbents for industrial applications [1]. Therefore, there is an interest to conduct adsorption studies in a flow-through system. 
The primary objectives of the current work were to (i) investigate the fluoride sorption capacity of VPum and VSco in fixed-bed column set-up, (ii) compare the adsorption properties of both adsorbents with each other, (iii) assess the fluoride adsorption mechanisms with respect to varying solution $\mathrm{pH}$, adsorbent particle size, and flow rate, (iv) deeper analyze the adsorption processes employing mathematical models such as the Adams-Bohart and Thomas model, and (v) finally verify the suitability of the models for the design of flow-through systems for the removal of fluoride from aqueous solutions.

\section{Results and Discussions}

\subsection{Characterization of Adsorbents}

2.1.1. Crystalline Structures and Material Properties and Experimental Conditions

The crystalline phases of VPum and VSco were characterized using the X-ray diffraction (XRD) instrumental technique. The mineralogical composition of the adsorbents was characterized by matching the X-ray diffractogram (Figure 1a (VPum), b (VSco)) with the database of the $X^{\prime}$ pert HighScore Plus software package (Version: 2.2b (2.2.2)). The results showed that the main crystalline phases in VSco were Silicon Oxide $\left(\mathrm{SiO}_{2}\right)$, Albite low $\left(\mathrm{Na}\left(\mathrm{AlSi}_{3} \mathrm{O}_{8}\right)\right)$, whereas Hematite $\left(\mathrm{Fe}_{2} \mathrm{O}_{3}\right)$ and Silicon Oxide $\left(\mathrm{SiO}_{2}\right)$ and Albite high $\left(\mathrm{Na}\left(\mathrm{AlSi}_{3} \mathrm{O}_{8}\right)\right)$ are the dominant components of VPum. The presence of crystalline phases in VPum samples can be ascribed to the peaks at $2 \theta=24.9^{\circ}, 27.6^{\circ}, 27.7^{\circ}, 37.7^{\circ}, 41.9^{\circ}, 58.0^{\circ}$, $64.9^{\circ}$ and $65.0^{\circ}$, while that of VSco sample appeared at $2 \theta=22.2^{\circ}, 23.9^{\circ}, 23.9^{\circ}, 23.9^{\circ}, 28.2^{\circ}$, $30.0^{\circ}, 33.9^{\circ}$, and $35.8^{\circ}$. The detected dome in both samples between $2 \theta=10^{\circ}$ and $40^{\circ}$ is an indication of amorphous material. The amorphous phase(s) present in the adsorbents was estimated by the calibration method. This method makes use of the integrated counts associated with the amorphous and crystalline fraction (Equation (1)) [37].

$$
\mathrm{C}_{\mathrm{m}}(\%)=\left[\frac{\mathrm{C}_{\mathrm{pa}}}{\mathrm{A}_{\mathrm{pa}}+\mathrm{C}_{\mathrm{pa}}}\right] \times 100
$$

where $C_{m}$ is the measured crystallinity, $C_{p a}$ and $A_{p a}$ are the integrated peak areas for the crystalline and amorphous components, respectively. The results revealed that the presence of the amorphous phase (s) in VPum and VSco is $89 \%$ and $68 \%$, respectively.

(a)

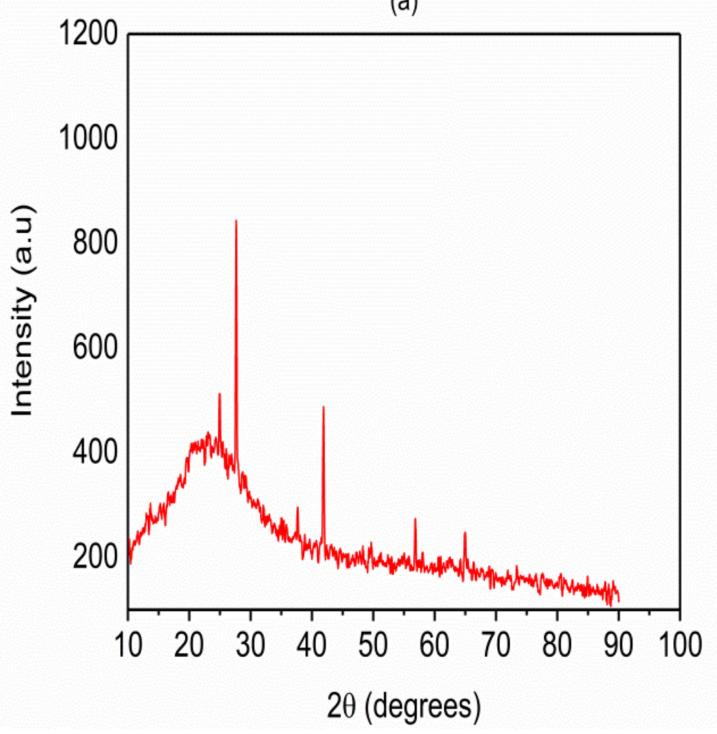

(b)

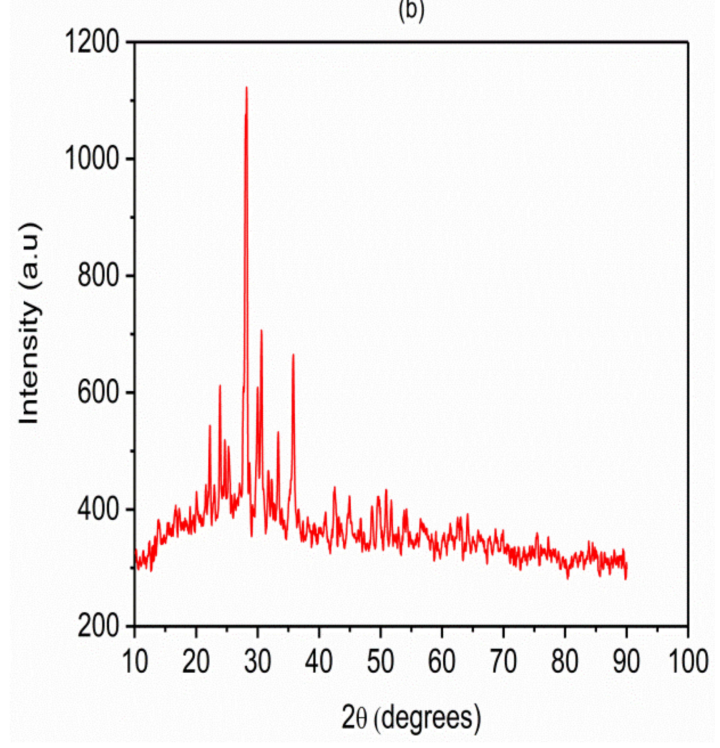

Figure 1. XRD patterns for (a) virgin pumice (VPum) and (b) virgin scoria (VSco).

The greater fraction of amorphous phase(s) in VPum compared with VSco possibly origins from simultaneous rapid cooling and depressurization of high-temperature volcano lava. The depressurization produces bubbles by lowering the boiling point of the lava. The 
simultaneous cooling then freezes the bubbles in the matrix of VPum. Due to rapid cooling, crystals do not have enough time to grow. A similar observation has been reported from the XRD analysis of pumice in previous studies [38,39].

Additionally, the results of material properties and experimental conditions were summarized in Table 1 as shown below.

Table 1. Material properties and experimental conditions.

\begin{tabular}{|c|c|c|c|c|c|c|}
\hline Parameters & \multicolumn{3}{|c|}{ Virgin Scoria (VSco) } & \multicolumn{3}{|c|}{ Virgin Pumice (VPum) } \\
\hline Particle Size (mm) & $<0.075$ & $\begin{array}{c}0.075- \\
0.425\end{array}$ & $0.425-2.00$ & $<0.075$ & $\begin{array}{c}0.075- \\
0.425\end{array}$ & $0.425-2.00$ \\
\hline Mass of adsorbents, $\mathrm{m}_{\mathrm{ads}}(\mathrm{gm})$ & 737.90 & 763.90 & 680.50 & 376.40 & 265.90 & 186.40 \\
\hline Bulk density, $\rho_{\mathrm{b}}\left(\mathrm{gm} \mathrm{cm}^{-3}\right)$ & 1.43 & 1.48 & 1.32 & 0.73 & 0.52 & 0.36 \\
\hline Particle density, $\rho_{\mathrm{s}}\left(\mathrm{gm} \mathrm{cm}^{-3}\right)$ & 2.37 & 2.33 & 1.94 & 1.61 & 1.31 & 0.64 \\
\hline Void volume, $\mathrm{V}_{\mathrm{V}}\left(\mathrm{cm}^{3}\right)$ & 203.70 & 187.20 & 164.70 & 281.10 & 311.80 & 222.30 \\
\hline Total porosity, $\varepsilon$ & 0.40 & 0.36 & 0.32 & 0.55 & 0.61 & 0.43 \\
\hline Flow rate, $\mathrm{Q}\left(\mathrm{cm}^{3} \mathrm{~min}^{-1}\right)$ & 1.25 & 2.50 & 3.75 & 1.25 & 2.50 & 3.75 \\
\hline Empty Bed Contact Time, ЕВСт (min) & 412.00 & 206.00 & 137.33 & 412.00 & 206.00 & 137.33 \\
\hline Filter (Superficial) velocity, $\mathrm{V}_{\mathrm{f}}\left(\mathrm{cm} \mathrm{min}^{-1}\right)$ & 0.02 & 0.05 & 0.07 & 0.02 & 0.05 & 0.07 \\
\hline Effective (Interstitial) velocity, $\mathrm{V}_{\mathrm{I}}\left(\mathrm{cm} \mathrm{min}^{-1}\right)$ & 0.06 & 0.13 & 0.23 & 0.05 & 0.08 & 0.17 \\
\hline
\end{tabular}

\subsubsection{Chemical Composition}

The chemical analysis revealed that the major elements in VPum and VSco, as determined by ICP-OES (Table S1), are Si, Al, and Fe. Other elements were present in comparatively smaller quantities or below the detection limit of the instrument. In our previous study [28], the XRF measurement (Table S1) indicated that the oxides of Si, Fe, and $\mathrm{Al}$ were the major constituents of both VPum and VSco.

However, the chemical composition of the adsorbents might changes in time due to weathering processes. Consequently, representative samples have to be checked for possible changes induced due to weathering.

\subsubsection{Fourier Transform Infrared (FTIR) Analysis}

The FTIR spectrums of VPum (Figure 2a) and VSco (Figure 2b) at wavelengths ranging from 4000 to $400 \mathrm{~cm}^{-1}$ are shown in Figure 2. Due to the symmetric stretching vibration of $\mathrm{Si}-\mathrm{O}-\mathrm{Si}$, the absorption band at $\sim 1045.75 \mathrm{~cm}^{-1}$ can be assigned to the characteristic peak of $\left(\mathrm{SiO}_{4}\right)^{2-}$ groups in the FTIR spectrum of VPum [39], whereas the band located at $1011.5 \mathrm{in}$ the FTIR spectrum of VSco can be belongs to the asymmetric stretching vibration of T-O-Si, $\mathrm{T}=\mathrm{Si}$ or Al [40]. In the FTIR spectrum of VPum, the peaks at $\sim 781$ and $\sim 695.25$ belong to bending vibrations of Si-O-Si bond [38], whereas the band shown in the FTIR spectrum of VSco at $\sim 759$ is related to the stretching vibration of 6-fold coordinated $\mathrm{Al}(\mathrm{VI})-\mathrm{OH}$ and 6-fold coordinated Al(VI)-O [41]. The small peaks shown in the FTIR spectrum of VSco at $\sim 572$ and $\sim 539.25$ can be attributed to the symmetric stretching of Si-O-Si and Al-O-Si $[40,42]$, whereas the small band at $\sim 465$ belongs to bending vibrations of Si-O-Si and O-Si-O [42]. Certain peaks like the broadening peak at $\sim 3602.5 \mathrm{~cm}^{-1}$ in the FTIR spectrum of VPum and sharper peak at $\sim 2369.75 \mathrm{~cm}^{-1}$ in the FTIR spectrum of VSco belongs to the asymmetric stretching vibration of $-\mathrm{OH}$ bond can be allocated to adsorbed water molecules, whereas the peak at $\sim 1645.75 \mathrm{~cm}^{-1}$ in VPum can be allocated to the bending vibration of $\mathrm{H}-\mathrm{O}-\mathrm{H}$ bond $[38,39,42]$. The most characteristic difference observed between the FTIR spectrum of VPum and FTIR spectra of VSco concerning the band attributed to the asymmetric stretching vibration of $-\mathrm{OH}$ bond. This band that is appeared as a broad band at about $\sim 3602.5 \mathrm{~cm}^{-1}$ in the FTIR spectrum of VPum becomes sharper and shifts to lower frequencies $\left(\sim 2369.75 \mathrm{~cm}^{-1}\right)$ in the FTIR spectrum of VSco indicating that there is a high water content in VPum and could be correlated with less mechanical strength than VSco. Similar observations have been reported for a different system [42]. 


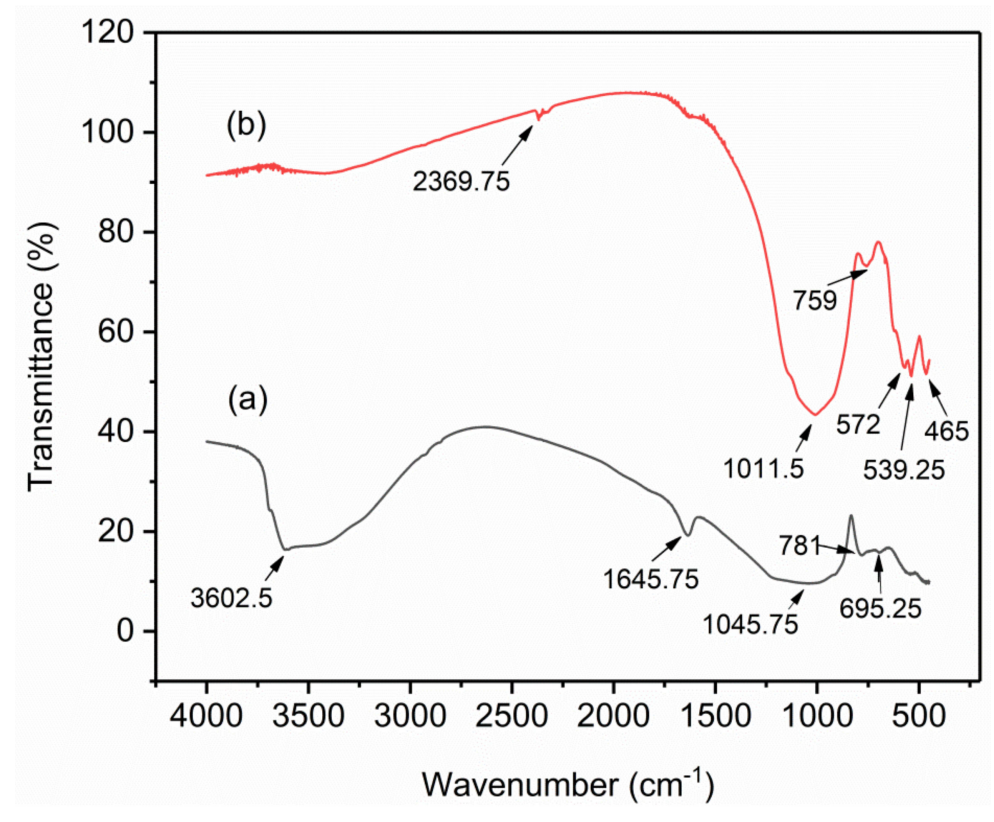

Figure 2. Fourier-transform infrared (FTIR) for (a) VPum and (b) VSco.

\subsubsection{Scanning Electron Microscope (SEM) Analysis}

The VPum (Figure 3a) and VSco (Figure 3b) SEM micrographs allowed direct observation of the surface morphology of the adsorbents with a magnification of $\times 100$. The structure of VPum showed that the surface of VPum had an interconnected porous surface $[38,43]$, while VSco had an irregular shape and fibrous cavities (or pores). In addition, it may be said that these pores in VSco were either closed or in open forms (pores) [44]. As seen from the micrographs of the adsorbents, VPum had an interconnected inner porous surface (as indicated in Figure 3a, red-colored), while VSco (Figure 3b) is dominated by the dead-end pores. Consequently, the interconnected internal pore structure in VPum allows for better fluoride accessibility and, hence, better adsorption capacity than VSco.
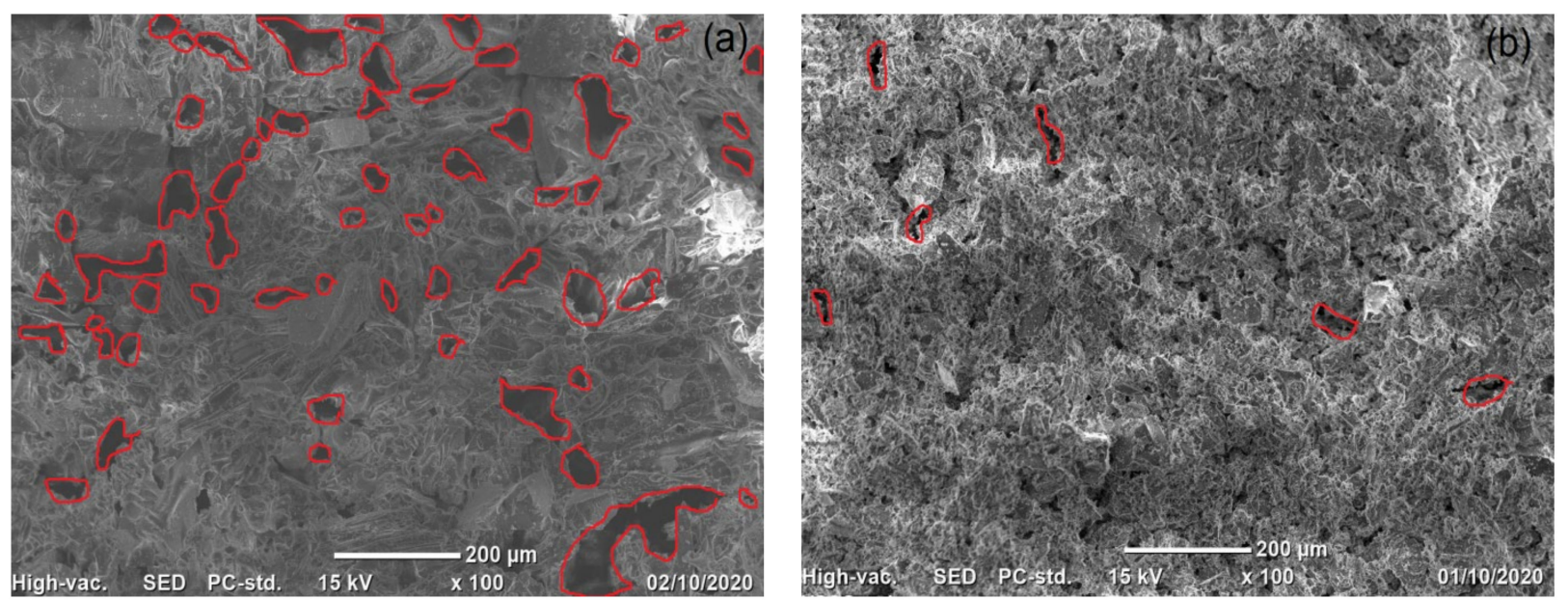

Figure 3. SEM micrographs for (a) VPum and (b) VSco.

\subsection{5. $\mathrm{pH}$ and Point of Zero Charges $\left(\mathrm{pH}_{\mathrm{PZC}}\right)$}

The $\mathrm{pH}$ of the rock samples in water was found to be 6.65 and 7.20 for VPum and VSco, respectively. The point of zero charges $\left(\mathrm{pH}_{\mathrm{PZC}}\right)$ of the adsorbents was identified as 6.85 for VPum and 6.98 for VSco at the intersection of the graph of the initial pH vs. the final $\mathrm{pH}$ (Figure 4). The slight difference observed in the adsorbents $\mathrm{pH}_{\mathrm{pzc}}$ is related to their different characteristics. As can be seen from Table S1, the two volcanic rocks 
(VPum and VSco) have different chemical compositions, which also influence the surface charge of the adsorbents. This is in agreement with previous studies [30,45], showing the effect of chemical composition on the zeta-potential of different materials. Below these values ( $\mathrm{pH}<6.85$ for VPum and $<6.98$ for VSco), the surface of the adsorbents is positively charged. Thus, if the $\mathrm{pH}<\mathrm{pH}$ PZC, fluoride could possibly be adsorbed onto the surface of the adsorbents by coulombic attraction $[6,46,47]$. In addition, the curve for the blank experiment (for blank electrolyte solution $0.01 \mathrm{M} \mathrm{NaCl}$ ) of both adsorbents is shown in Figure 4. As seen from the blank curve (Figure 4), a pH change without adding the adsorbents was obtained, which confirmed the sorbent dosing is not the only factor to fluctuate the $\mathrm{pH}$ of the solution.
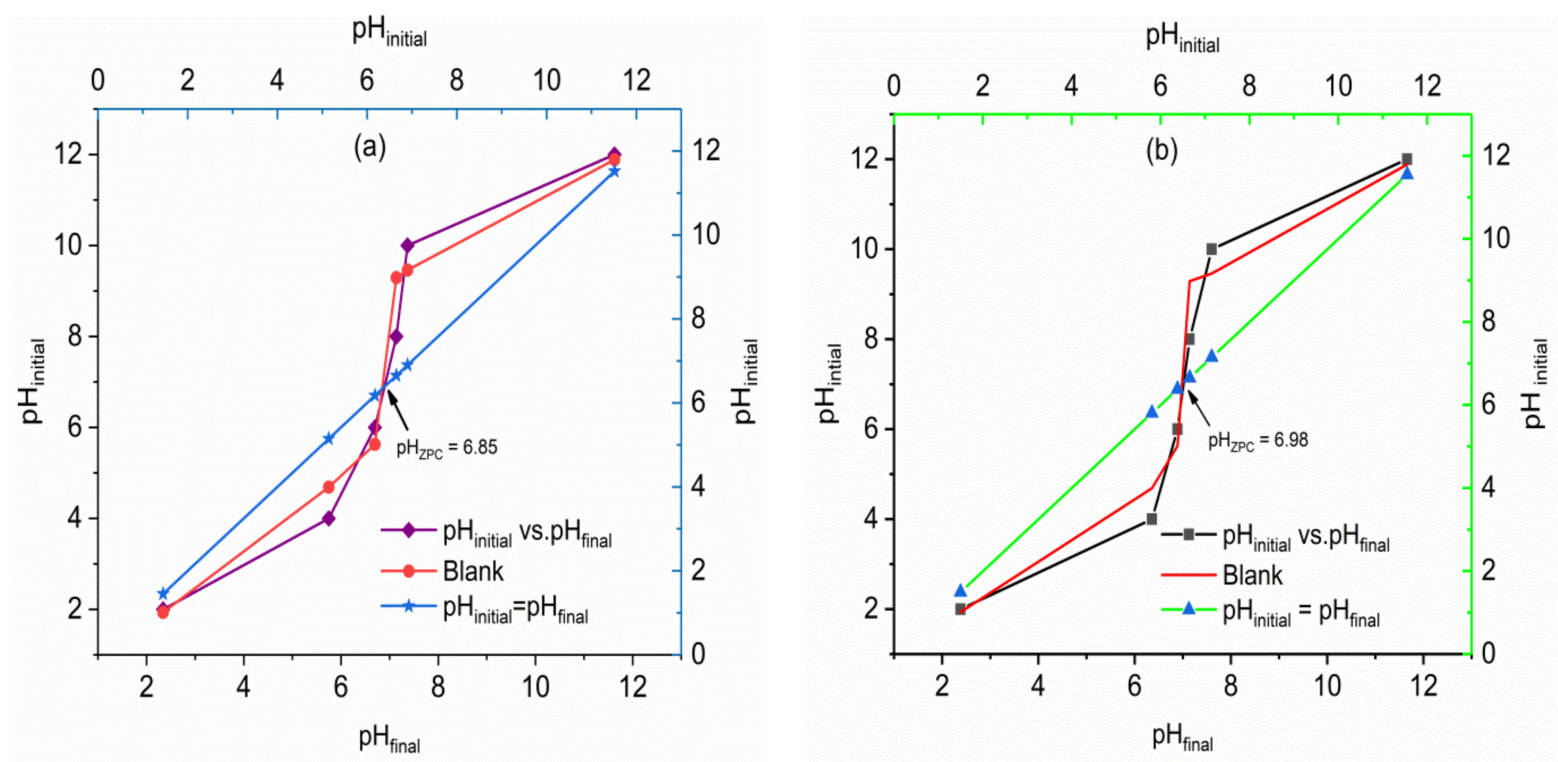

Figure 4. Determination of $\mathrm{pH}$ point of zero charges $\left(\mathrm{pH}_{\mathrm{PzC}}\right)$ for (a) VPum and (b) VSco.

\subsection{Effect of Adsorbents Particle Size}

The effect of the particles size on the breakthrough behavior of fluoride was investigated for both VSco and VPum with grain size classes of silt to medium sand $(<0.075$, $0.075-0.425,0.425-2.00 \mathrm{~mm}$ ), while maintaining the same initial fluoride concentration $(10 \mathrm{mg} / \mathrm{L})$, bed depth $(10 \mathrm{~cm})$, initial flow rate $(1.25 \mathrm{~mL} / \mathrm{min})$, as well as solution $\mathrm{pH}(2.00)$ (Figure 5a (VPum), b (VSco)). As seen from Figure 5a (VPum) and b (VSco), on reducing the particle size from medium $(0.425-2.00 \mathrm{~mm})$ to silt $(<0.075 \mathrm{~mm})$ the breakthrough and exhaustion time noticeably increased for VSco, while the breakthrough and exhaustion time was high for VPum at a fine particle size $(0.075-0.425 \mathrm{~mm})$. The resulting breakthrough and removal of fluoride parameters are tabulated in Table 2. As can also be seen from Table 2, the amount of total adsorbed fluoride $\left(\mathrm{q}_{\mathrm{tot}}\right)$ and the uptake of fluoride was high at silt $(<0.075 \mathrm{~mm})$ and fine $(0.075-0425 \mathrm{~mm})$ particle size for VSco and VPum, respectively. The smaller particle sizes provide large surface areas and/or sorption sites are more readily available. The results showed that the reduction of particle size of an adsorbent is a significant controlling factor in the fluoride-VSco system (at a particle size of $<0.075 \mathrm{~mm}$ the fluoride uptake was high). A similar effect was observed for VPum (at a particle size of $0.075-0.425 \mathrm{~mm}$ the fluoride sorption capacity was high). However, the effect of particle size on the adsorption capacity is more pronounced for VSco than VPum. That means the pore spaces are more readily available in VPum as compared to VSco, showing that the pore space of VPum is a continuum (skeletal structure) while the pore space of VSco is dominated by dead-end pores. This infers VPum loses its internal porosity at the smallest particle size $(<0.075 \mathrm{~mm})$ since the continuum pore space (skeletal structure) is damaged when compared to the fine particle size $(0.075-0425 \mathrm{~mm})$ and resulting in smaller internal 
pore surface areas; consequently, the removal capacity of the adsorbent decreased. On the other hand, the pore space is not readily available in VSco (i.e., the internal pore space of VSco is dominated by dead-end pores). VSco at the smallest particle size $(<0.075 \mathrm{~mm})$ is, therefore, expected to have a large surface area, which leads to higher removal capacity compared to the fine particle size $(0.075-0425 \mathrm{~mm})$. A similar observation was reported for both adsorbents based on a batch adsorption experiment [28], and a similar remark was also drawn for pumice in the previous study [38]. Moreover, the BET specific surface area $\left(\mathrm{S}_{\mathrm{BET}}\right)$ of the adsorbents was determined. As expected, VPum $\left(3.50 \mathrm{~m}^{2} / \mathrm{g}\right)$ has a larger surface area than VSco $\left(2.49 \mathrm{~m}^{2} / \mathrm{g}\right)$. Thus, all experiments other than the effect of particle sizes were conducted at a particle size of $<0.075 \mathrm{~mm}$ for VSco and $0.075-0.425 \mathrm{~mm}$ for VPum.

(a)

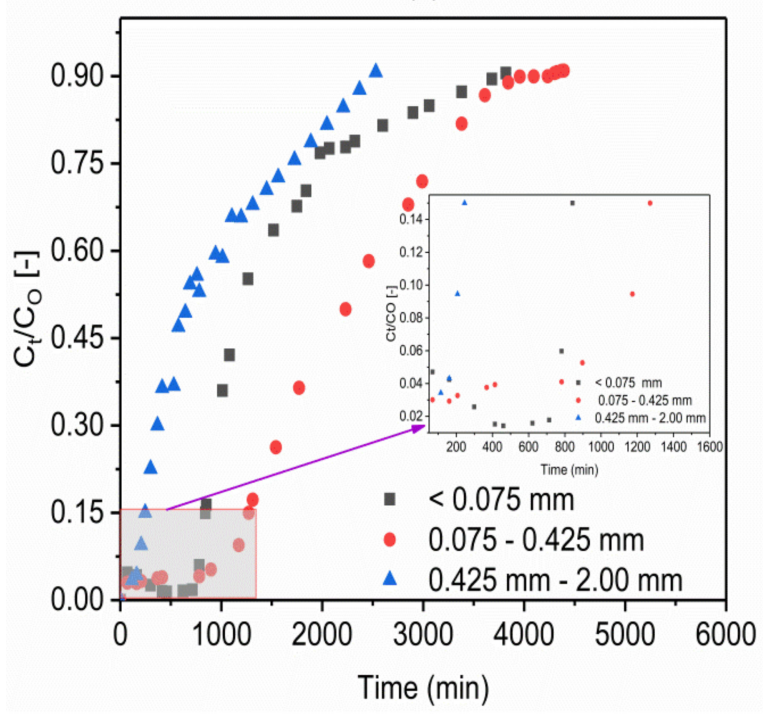

(b)

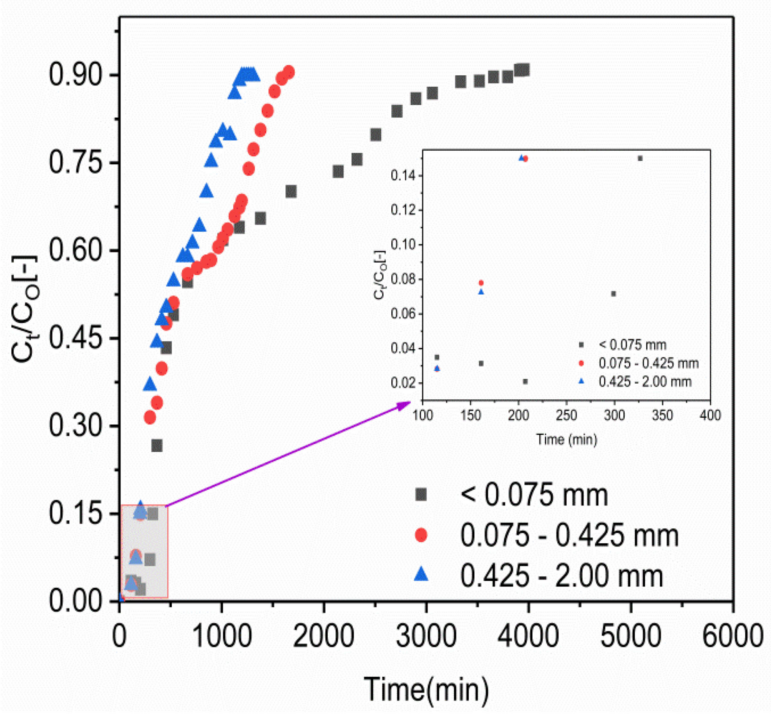

Figure 5. Effect of particle sizes on the breakthrough behavior of fluoride in (a) VPum and (b) VSco at (pH 2.00; influent fluoride concentration $10 \mathrm{mg} / \mathrm{L}\left(\mathrm{C}_{\mathrm{O}}: 10 \mathrm{mg} / \mathrm{L}\right)$; flow rate $1.25 \mathrm{~mL} / \mathrm{min}$ (QO: $1.25 \mathrm{~mL} / \mathrm{min}$; bed depth $10 \mathrm{~cm}$ ).

Table 2. Fixed-bed column parameters obtained for fluoride adsorption onto VPum and VSco.

\begin{tabular}{|c|c|c|c|c|c|c|c|c|c|c|c|c|c|}
\hline VPum. & $\begin{array}{c}\mathrm{H} \\
(\mathrm{cm})\end{array}$ & $\begin{array}{c}\mathrm{C}_{\mathrm{O}} \\
(\mathrm{mg} / \mathrm{L})\end{array}$ & $\underset{(\mathrm{mL} / \mathrm{min})}{\mathrm{Qo}_{0}}$ & $\mathrm{pH}$ & $\begin{array}{l}\text { Particles size } \\
\left(P_{\text {size }}\right)(\mathrm{mm})\end{array}$ & $\begin{array}{c}t_{b} \\
(\min )\end{array}$ & $\begin{array}{c}t_{e} \\
(\min )\end{array}$ & $\begin{array}{l}\mathrm{V}_{\mathrm{b}} \\
(\mathrm{mL})\end{array}$ & $V_{e}(m L)$ & $\begin{array}{l}\text { MTZ } \\
(\mathrm{cm})\end{array}$ & $\begin{array}{l}\text { EBCT } \\
(\mathrm{min})\end{array}$ & $\underset{(\mathrm{mg})}{\mathrm{q}_{\mathrm{tot}}}$ & $\underset{(\mathrm{mg} / \mathrm{kg})}{\mathrm{q}_{\mathrm{e}}}$ \\
\hline & 10 & 10 & 1.25 & 2.00 & $<0.075$ & 816 & 1623 & 1019.64 & 2033.41 & 4.99 & 412 & 20.28 & 59.6 \\
\hline & 10 & 10 & 1.25 & 2.00 & $0.075-0.425$ & 1206 & 2339 & 1507.50 & 2923.70 & 4.84 & 412 & 29.24 & 109.9 \\
\hline & 10 & 10 & 1.25 & 2.00 & $0.425-2.00$ & 235 & 1013 & 293.23 & 1265.89 & 7.68 & 412 & 12.67 & 67.9 \\
\hline & 10 & 10 & 1.25 & 4.00 & $0.075-0.425$ & 278 & 500 & 347.50 & 625 & 4.44 & 412 & 6.25 & 23.51 \\
\hline & 10 & 10 & 1.25 & 6.00 & $0.075-0.425$ & 135 & 315 & 168.75 & 393.75 & $\begin{array}{l}4.4+ \\
5.71\end{array}$ & 412 & 3.94 & 14.81 \\
\hline & 10 & 10 & 2.50 & 2.00 & $0.075-0.425$ & 215 & 634 & 538.47 & 1585.16 & 6.60 & 206 & 7.93 & 29.8 \\
\hline & 10 & 10 & 3.75 & 2.00 & $0.075-0.425$ & 75 & 359 & 282.69 & 1346.42 & 7.90 & 137 & 4.49 & 16.89 \\
\hline \multirow[t]{8}{*}{ VSco } & $\begin{array}{c}\mathrm{H} \\
(\mathrm{cm})\end{array}$ & $\begin{array}{c}\mathrm{C}_{\mathrm{O}} \\
(\mathrm{mg} / \mathrm{L})\end{array}$ & $\underset{(\mathrm{mL} / \mathrm{min})}{\mathrm{Q}_{\mathrm{o}}}$ & $\mathrm{pH}$ & $\begin{array}{l}\text { Particles size } \\
\left(P_{\text {size }}\right)(\mathrm{mm})\end{array}$ & $\begin{array}{c}t_{b} \\
(\min )\end{array}$ & $\begin{array}{c}t_{e} \\
(\min )\end{array}$ & $\begin{array}{l}\mathrm{V}_{\mathrm{b}} \\
(\mathrm{mL})\end{array}$ & $\mathrm{V}_{\mathrm{e}}(\mathrm{mL})$ & $\begin{array}{l}\text { MTZ } \\
\text { (cm) }\end{array}$ & $\begin{array}{l}\text { EBCT } \\
(\mathrm{min})\end{array}$ & $\underset{(\mathrm{mg})}{\mathrm{q}_{\mathrm{tot}}}$ & $\underset{(\mathrm{mg} / \mathrm{kg})}{\mathrm{q}_{\mathrm{e}}}$ \\
\hline & 10 & 10 & 1.25 & 2.00 & $<0.075$ & 415 & 1286 & 518.03 & 1607.60 & 6.77 & 412 & 16.08 & 22 \\
\hline & 10 & 10 & 1.25 & 2.00 & $0.075-0.425$ & 199 & 760 & 248.99 & 849.80 & 7.38 & 412 & 9.50 & 12.4 \\
\hline & 10 & 10 & 1.25 & 2.00 & $0.425-2.00$ & 231 & 591 & 288.17 & 739.12 & 6.10 & 412 & 7.39 & 10.9 \\
\hline & 10 & 10 & 1.25 & 4.00 & $<0.075$ & 296 & 487 & 370 & 608.75 & 3.92 & 412 & 6.09 & 8.2 \\
\hline & 10 & 10 & 1.25 & 6.00 & $<0.075$ & 227 & 393 & 283.75 & 491.25 & 4.22 & 412 & 4.91 & 6.7 \\
\hline & 10 & 10 & 2.50 & 2.00 & $<0.075$ & 185 & 445 & 462.95 & 1113.19 & 5.84 & 206 & 5.57 & 7.5 \\
\hline & 10 & 10 & 3.75 & 2.00 & $<0.075$ & 69 & 249 & 256.82 & 931.87 & 7.24 & 137 & 3.10 & 4.2 \\
\hline
\end{tabular}

$t_{b}=$ breakthrough time, $t_{e}=$ exhaustion time, $V_{b}=$ total effluent volume at breakthrough time, $V_{e}=$ total effluent volume at exhaustion time MTZ = Mass Transfer Zone, EBCT = Empty Bed Contact Time, $\mathrm{q}_{\text {total }}=$ total amount of fluoride adsorbed from the column, $\mathrm{q}_{\mathrm{e}}=\mathrm{equilibrium}$ fluoride uptake per $\mathrm{kg}$ of adsorbent. 


\subsection{Effect of Influent $p H$}

The influent solution's $\mathrm{pH}$ can noticeably affect the anions sorption on the adsorbents by changing the degree of ionization, the ion speciation, and the adsorbent's surface charge. Therefore, the effect of solution $\mathrm{pH}$ on adsorption of fluoride using VPum and VSco was investigated at different $\mathrm{pH}(2.00,4.00$, and 6.00$)$ by a separate set of fixed-bed adsorption columns. The breakthrough curves obtained for both adsorbents are shown in Figure $6 \mathrm{a}, \mathrm{b}$ for a fixed inlet flow rate of $1.25 \mathrm{~mL} / \mathrm{min}$, influent fluoride concentration of $10 \mathrm{mg} / \mathrm{L}$, column bed depth of $10 \mathrm{~cm}$, and a particle size of $<0.075 \mathrm{~mm}$ for VSco and $0.075-0.425 \mathrm{~mm}$ for VPum.

(a)

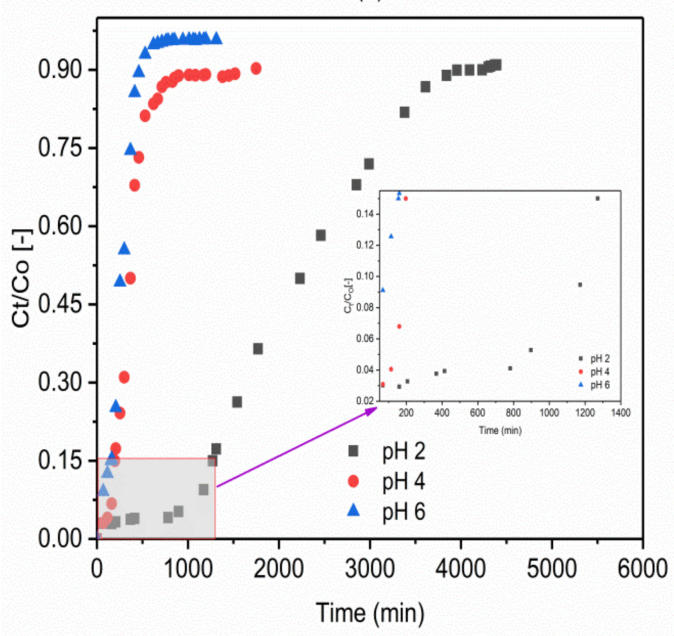

(b)

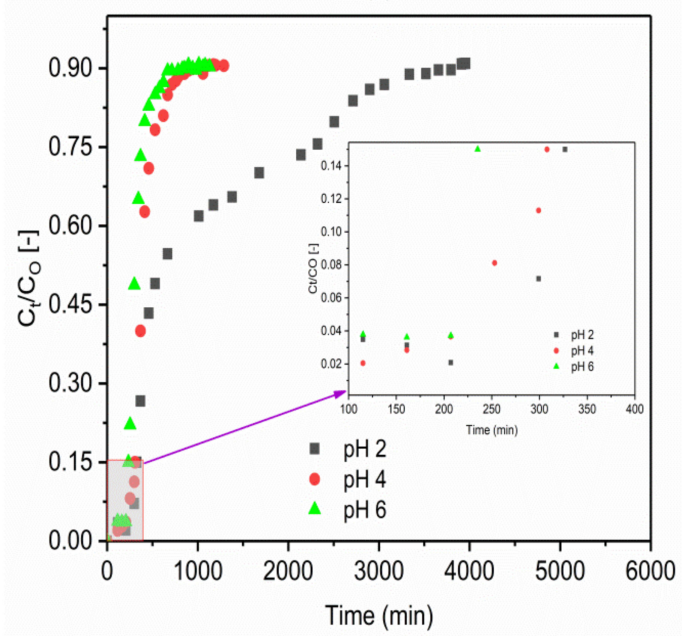

Figure 6. Effect of $\mathrm{pH}$ on the breakthrough behavior of fluoride in (a) VPum: $0.075-0.425 \mathrm{~mm}$ and (b) VSco: $<0.075 \mathrm{~mm}\left(\mathrm{C}_{\mathrm{O}}\right.$ : $10 \mathrm{mg} / \mathrm{L} ; \mathrm{Q}_{\mathrm{O}}: 1.25 \mathrm{~mL} / \mathrm{min}$; bed depth $10 \mathrm{~cm}$ ).

As can generally be observed from Figure $6 \mathrm{a}, \mathrm{b}$, the adsorption capacity of the adsorbents noticeably increased with decreasing $\mathrm{pH}$. As can also be seen from Table 2 (VPum and VSco), the total amount of fluoride adsorbed ( $\left.\mathrm{q}_{\mathrm{tot}}\right)$ was high for VPum $(29.24 \mathrm{mg})$ and $16.08 \mathrm{mg}$ for VSco at lower $\mathrm{pH}$ of 2, and the breakthrough time decreased from 1206 to $135 \mathrm{~min}$ for VPum and 415 to $227 \mathrm{~min}$ for VSco with an increase in pH from 2 to 6 . The volume of water treated at the breakthrough time was higher at $\mathrm{pH}$ of $2.00(1507.5 \mathrm{~mL}$ for VPum and $518.03 \mathrm{~mL}$ for VSco) than 4.00 ( $347.5 \mathrm{~mL}$ for VPum and $370 \mathrm{~mL}$ for VSco) and 6.00 (168.75 mL for VPum and $283.75 \mathrm{~mL}$ for VSco). This concludes the occurrence of the breakthrough time was longer, the amount of fluoride adsorbed, and treated water volume was high for a $\mathrm{pH}$ of 2.00. As $\mathrm{pH}$ varies, surface charge also varies; the sorption of charged species is affected. Therefore, the performance of adsorbents for better adsorption at low $\mathrm{pH}$ may be the result of the presence of a large number of $\mathrm{H}^{+}$ions at low $\mathrm{pH}$ values, and hence neutralize the negatively charged adsorbent surface [48], consequently dropping the interference of the adsorption of fluoride. In addition, this reality can be elucidated based on the $\mathrm{pH}$ value at the point of zero charges of the adsorbents ( $\mathrm{pH}_{\mathrm{PZC}}=6.85$ (VPum) and 6.98 (VSco)).

Moreover, the decrease in the adsorption of fluoride at $\mathrm{pH} 4.00$ and 6.00 could also be due to the decrease in the number of $\mathrm{H}^{+}$or electrostatic repulsion of fluoride by negatively charged adsorbent surface $[47,49]$.

Hence, the sorption of fluoride ions is due to an electrostatic phenomenon and surface complexation that perform independently or together for the adsorption of fluoride ions on the adsorbents. The removal mechanism at $\mathrm{pH}<\mathrm{pH}$ PZC is presumably due to columbic attraction of fluoride by positive surface charges (Equation (2)) and/or ligand exchange reactions of fluoride with surface hydroxyl groups (Equation (3)).

$$
\mathrm{MOH}_{2}^{+}+\mathrm{F}^{-} \leftrightarrow \mathrm{MOH}_{2}^{+}---\mathrm{F}^{-}
$$




$$
\mathrm{MOH}_{2}^{+}+\mathrm{F}^{-} \leftrightarrow \mathrm{MF}+\mathrm{H}_{2} \mathrm{O}
$$

where, $\mathrm{M}$ represents $\mathrm{Fe}, \mathrm{Al}, \mathrm{Si}, \mathrm{Ca}, \mathrm{Mg}$, etc.

In this study, an increment in the final $\mathrm{pH}(\mathrm{pH} \sim 7.20)$ was observed after the completion of the adsorption experiment, which is consistent with the columbic or ligand exchange type adsorption mechanism shown in Equations (2) and (3) [47]. This can be further explained by the capacity of the adsorbents to maintain a neutral $\mathrm{pH}$ after adsorption $[6,50]$. The capacity to maintain neutral effluent solution $\mathrm{pH}$ could be from the amphoteric nature of oxides in both adsorbents $\left(\mathrm{Al}_{2} \mathrm{O}_{3}, \mathrm{Fe}_{2} \mathrm{O}_{3}, \mathrm{TiO}_{2}\right.$, etc. $)$ when compared with the effect of basic metallic oxides (Table S1). This type of observations were reported for the removal of pollutant in a previous study [6]. Furthermore, the elemental compositions of exchangeable cations also play a critical role in fluoride uptake during defluoridation [51]. There might be a slight increase in electro conductivities of the final solutions, which might not influence the adsorption process [52]. However, additional testing of the effluent solution for various compounds may be required to draw definite conclusions.

It is noted that the effect of $\mathrm{pH}$ on the adsorption capacity may be due to the shared impact of $\mathrm{pH}$ on the nature of the adsorbent surface, the existence of the adsorbed pollutant (fluoride ion), and the added acid and base to the working solution to adjust its $\mathrm{pH}$. In this study, the optimum and effective removal of fluoride takes place at a $\mathrm{pH}$ of 2.00; hence, all experiments other than the effect of $\mathrm{pH}$ were conducted at a $\mathrm{pH}$ of 2.00 for both adsorbents.

\subsection{Effect of Flow Rate}

The effect of flow rate on the adsorption of fluoride using VPum and VSco was examined at the flow rates of $1.25,2.50$, and $3.75 \mathrm{~mL} / \mathrm{min}$ whereas the bed depth $(10 \mathrm{~cm})$, influent solution $\mathrm{pH}(2.00)$, initial fluoride concentration $(10 \mathrm{mg} / \mathrm{L})$, and adsorbents particle size $(<0.075 \mathrm{~mm}$ (Vsco) and $0.075-0.425 \mathrm{~mm}$ (VPum)) were held constant. As indicated in Figure 7a (VPum) and b (VSco), the breakthrough curves become steeper and shifted to the origin with an increasing flow rate while the breakthrough time decreased. The use of a high flow rate decreases the contact time of fluoride in the solution with the adsorbents, thereby allowing earlier breakthroughs to occur. Additionally, increasing the flow rate from 1.25 to $3.75 \mathrm{~mL} / \mathrm{min}$ decreased the volume of water treated from 1507.5 to $282.69 \mathrm{~mL}$ and 518.03 to $256.03 \mathrm{~mL}$ for VPum and VSco, respectively (Table 2).

(a)

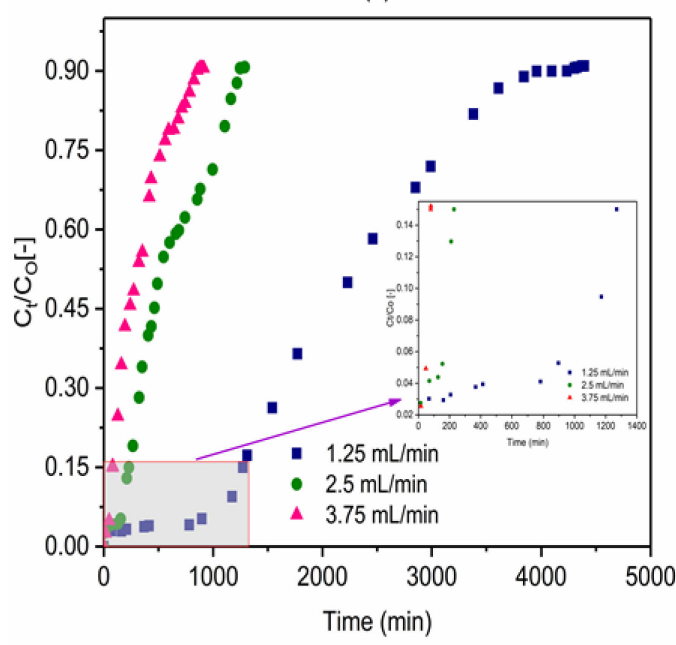

(b)

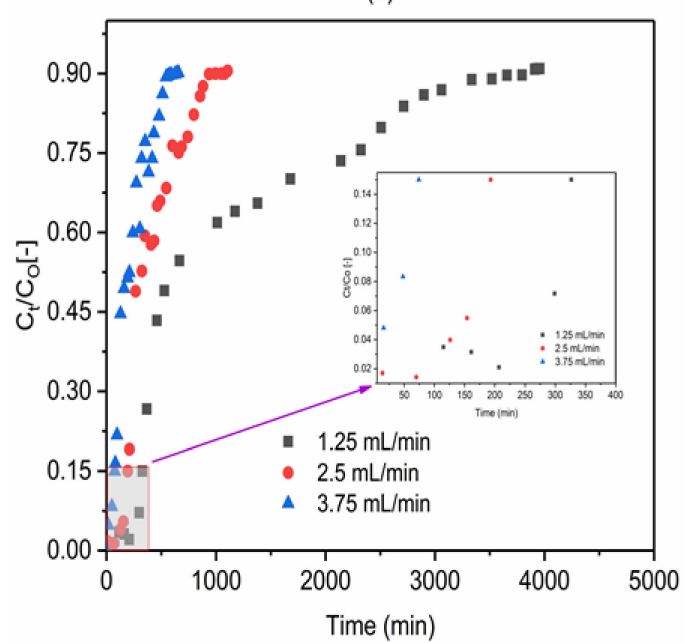

Figure 7. Effect of influent flow rate on the breakthrough behavior of fluoride in (a) VPum: 0.075-0.425 mm and (b) VSco: $<0.075 \mathrm{~mm}\left(\mathrm{pH} 2 ; \mathrm{C}_{\mathrm{O}}: 10 \mathrm{mg} / \mathrm{L}\right.$; bed depth $\left.10 \mathrm{~cm}\right)$.

This was further supported by Mass Transfer Zone (MTZ) (Table 2) which increased with increasing flow rate. The total fluoride adsorbed $\left(\mathrm{q}_{\mathrm{tot}}\right)$ increased from $4.49 \mathrm{mg}$ to $29.24 \mathrm{mg}$ for VPum and from $3.10 \mathrm{mg}$ to $16.08 \mathrm{mg}$ for VSco (Table 2) as the flow rate decrease 
from 3.75 to $1.25 \mathrm{~mL} / \mathrm{min}$. This results in the increase of the adsorption performance of the column from 17 to $110 \mathrm{mg} / \mathrm{kg}$ and 4.2 to $22 \mathrm{mg} / \mathrm{kg}$ for VPum and VSco, respectively (Table 2). The increase in sorption efficiency at a low flow rate shows that the adsorbates have sufficient time to penetrate and diffuse deeply into the pores of the adsorbents; hence, intraparticle mass transfer controls the sorption process. This was also verified by MTZ (Table 2) or unused bed, which decreased with decreasing flow rate. In general, at the lower flow rate, the contact time between the adsorbent and the fluoride was higher, resulting in an increased breakthrough time and treated water volume for the continuous column adsorption system. A similar type of observation was reported by various authors for fixed-bed column systems [53-55]. In this study, the optimum and effective removal of fluoride takes place at a flow rate of $1.25 \mathrm{~mL} / \mathrm{min}$; so, all experiments other than the effect of flow rate were performed at a flow rate of $1.25 \mathrm{~mL} / \mathrm{min}$.

\subsection{Application of the Thomas Model}

The values of the Thomas model parameters, $\mathrm{K}_{\mathrm{T}}$ and $\mathrm{q}_{\mathrm{o}}$ for both adsorbents shown in Table 3 for different experimental parameters were found from the non-linear optimization techniques according to Equation (18). The non-linear plots of the experimental (designated as exp.) and simulated (designated as cal.) breakthrough curves based on the Thomas model for VPum (a) and VSco (b) at different particle sizes (Figure S1), influent pH (Figure S2), and influent volumetric flow rate (Figure S3) were provided in Supplementary Materials. The results of $\mathrm{K}_{\mathrm{T}}, \mathrm{q}_{\mathrm{o}}$, and correlation coefficient $\left(\mathrm{R}^{2}\right)$ are shown in Table 3 for VPum and VSco. From the results, it can be seen that the values of $R^{2}$ range from 0.897 to 0.993 for VPum and 0.901 to 0.973 for VSco.

Table 3. Thomas model parameters for fluoride adsorption onto VPum and VSco.

\begin{tabular}{|c|c|c|c|c|c|c|c|c|c|}
\hline VPum & $\mathrm{H}(\mathrm{cm})$ & $\mathrm{C}_{\mathrm{o}}(\mathrm{mg} / \mathrm{L})$ & $\underset{(\mathrm{mL} / \mathrm{min})}{\mathrm{Q}}$ & $\mathrm{pH}$ & $P_{\text {size }}(\mathbf{m m})$ & $\begin{array}{c}\mathrm{K}_{\mathrm{T}}(\mathrm{L} / \mathrm{min} . \mathrm{mg}) \\
\left(\times 10^{4}\right)\end{array}$ & $\begin{array}{c}\mathrm{q}_{0(\mathrm{cal} .)} \\
(\mathrm{mg} / \mathrm{kg})\end{array}$ & $\begin{array}{c}\left.\mathrm{q}_{\mathrm{e}(\exp )}\right) \\
(\mathrm{mg} / \mathrm{kg})\end{array}$ & $\mathbf{R}^{2}$ \\
\hline & 10 & 10 & 1.25 & 2.00 & $<0.075$ & 2.199 & 48.6 & 59.6 & 0.950 \\
\hline & 10 & 10 & 1.25 & 2.00 & $0.075-0.425$ & 1.440 & 109.9 & 109.9 & 0.993 \\
\hline & 10 & 10 & 1.25 & 2.00 & $0.425-2.00$ & 1.840 & 57.9 & 67.9 & 0.897 \\
\hline & 10 & 10 & 1.25 & 4.00 & $0.075-0.425$ & 8.289 & 17.83 & 23.51 & 0.977 \\
\hline & 10 & 10 & 1.25 & 6.00 & $0.075-0.425$ & 12.099 & 13.08 & 14.81 & 0.995 \\
\hline & 10 & 10 & 2.50 & 2.00 & $0.075-0.425$ & 3.565 & 55.81 & 29.8 & 0.953 \\
\hline & 10 & 10 & 3.75 & 2.00 & $0.075-0.425$ & 5 & 45.82 & 16.9 & 0.962 \\
\hline \multirow[t]{8}{*}{ VSco } & $\mathrm{H}(\mathrm{cm})$ & $\mathrm{C}_{\mathrm{o}}(\mathrm{mg} / \mathrm{L})$ & $\begin{array}{c}\mathrm{Q} \\
(\mathrm{mL} / \mathrm{min})\end{array}$ & $\mathrm{pH}$ & $\mathbf{P}_{\text {size }}(\mathbf{m m})$ & $\begin{array}{c}\mathrm{K}_{\mathrm{T}}(\mathrm{L} / \mathrm{min} . \mathrm{mg}) \\
\left(\times 10^{4}\right)\end{array}$ & $\begin{array}{l}\mathrm{q}_{0(\mathrm{cal} .)} \\
(\mathrm{mg} / \mathrm{kg})\end{array}$ & $\begin{array}{c}\text { qe(exp.) } \\
(\mathrm{mg} / \mathrm{kg})\end{array}$ & $\mathbf{R}^{2}$ \\
\hline & 10 & 10 & 1.25 & 2.00 & $<0.075$ & 1.23 & 19 & 22 & 0.901 \\
\hline & 10 & 10 & 1.25 & 2.00 & $0.075-0.425$ & 2.213 & 13.4 & 12.4 & 0.931 \\
\hline & 10 & 10 & 1.25 & 2.00 & $0.425-2.00$ & 3.310 & 10.1 & 10.9 & 0.956 \\
\hline & 10 & 10 & 1.25 & 4.00 & $<0.075$ & 10.140 & 7.06 & 8.2 & 0.973 \\
\hline & 10 & 10 & 1.25 & 6.00 & $<0.075$ & 15.520 & 5.42 & 6.7 & 0.965 \\
\hline & 10 & 10 & 2.50 & 2.00 & $<0.075$ & 5.263 & 13.3 & 7.5 & 0.929 \\
\hline & 10 & 10 & 3.75 & 2.00 & $<0.075$ & 7.220 & 11.2 & 4.2 & 0.944 \\
\hline
\end{tabular}

The high values of $R^{2}$ indicate there were no significant disparities between the experimental data points and calculated data by the Thomas model for all particle sizes, influent solution $\mathrm{pH}$, and influent volumetric flow rate. The observed differences between the experimental data and calculated data from the Thomas model may be due to the characteristic attribute weakness in the model. The Thomas model does not consider the external (film) and intra-particle diffusions in the adsorption system and, therefore, proposes adsorbate-adsorbent surface reactions to control the adsorption rate, hence the breakthrough. However, nearly all adsorption operations are typically not limited to surface reaction kinetics, but are also controlled by external and/or intra-particle diffusion [56,57]. Thus, the perceived disparities in this study indicate external and/or intra-particle mass transfer may be the rate-controlling steps in fluoride adsorption in a fixed-bed column 
onto the adsorbents. Similar observations were drawn with the kinetic study of fluoride under fixed-bed conditions onto modified pumice [57]. As shown in Table 3, the value of the Thomas rate constant $\left(\mathrm{K}_{\mathrm{T}}\right)$ increased as the influent flow rate increased but the value of the maximum solid-phase concentration $\left(\mathrm{q}_{\mathrm{o}}\right)$ decreased. A related type of investigation on Thomas constants for different systems was reported by various authors [58,59].

\subsection{Application of the Adams-Bohart Model}

The parameter values of the Adams-Bohart model, $\mathrm{K}_{\mathrm{AB}}$ and $\mathrm{N}_{\mathrm{O}}$, as depicted in Table 4 for Vpum and Vsco were similarly determined by non-linear regression analysis according to Equation (19).

Table 4. Adams-Bohart model parameters for fluoride adsorption onto VPum and VSco.

\begin{tabular}{|c|c|c|c|c|c|c|c|c|}
\hline VPum & $\mathrm{H}(\mathrm{cm})$ & $\mathrm{C}_{\mathrm{o}}(\mathrm{mg} / \mathrm{L})$ & $\underset{(\mathrm{mL} / \mathrm{min})}{\mathrm{Q}}$ & $\mathrm{pH}$ & $\begin{array}{l}P_{\text {size }} \\
(\mathrm{mm})\end{array}$ & $\begin{array}{c}\mathrm{K}_{\mathrm{AB}}(\mathrm{L} / \mathrm{min} . \mathrm{mg}) \\
\left(\times 10^{4}\right)\end{array}$ & $\begin{array}{c}\mathrm{N}_{0} \\
(\mathrm{mg} / \mathrm{L})\end{array}$ & $\mathbf{R}^{2}$ \\
\hline & 10 & 10 & 1.25 & 2.00 & $<0.075$ & 2.187 & 35.55 & 0.950 \\
\hline & 10 & 10 & 1.25 & 2.00 & $0.075-0.425$ & 1.439 & 56.85 & 0.993 \\
\hline & 10 & 10 & 1.25 & 2.00 & $0.425-2.00$ & 1.741 & 20.77 & 0.911 \\
\hline & 10 & 10 & 1.25 & 4.00 & $0.075-0.425$ & 8. 289 & 9.22 & 0.995 \\
\hline & 10 & 10 & 1.25 & 6.00 & $0.075-0.425$ & 12. 099 & 6.76 & 0.953 \\
\hline & 10 & 10 & 2.50 & 2.00 & $0.075-0.425$ & 3.565 & 29.68 & 0.962 \\
\hline & 10 & 10 & 3.75 & 2.00 & $0.075-0.425$ & 5.000 & 22.74 & 0.995 \\
\hline \multirow[t]{8}{*}{ VSco } & $\mathbf{H}(\mathrm{cm})$ & $\mathrm{C}_{\mathrm{o}}(\mathrm{mg} / \mathrm{L})$ & $\begin{array}{c}\mathrm{Q} \\
(\mathrm{mL} / \mathrm{min})\end{array}$ & $\mathrm{pH}$ & $\begin{array}{l}P_{\text {size }} \\
(\mathrm{mm})\end{array}$ & $\begin{array}{c}\mathrm{K}_{\mathrm{AB}}(\mathrm{L} / \mathrm{min} . \mathrm{mg}) \\
\left(\times 10^{4}\right)\end{array}$ & $\begin{array}{c}\mathrm{N}_{\mathrm{o}} \\
(\mathrm{mg} / \mathrm{L})\end{array}$ & $\mathbf{R}^{2}$ \\
\hline & 10 & 10 & 1.25 & 2.00 & $<0.075$ & 1.233 & 27.27 & 0.886 \\
\hline & 10 & 10 & 1.25 & 2.00 & $0.075-0.425$ & 2.213 & 17.68 & 0.886 \\
\hline & 10 & 10 & 1.25 & 2.00 & $0.425-2.00$ & 3.310 & 13.41 & 0.956 \\
\hline & 10 & 10 & 1.25 & 4.00 & $<0.075$ & 10.145 & 10.13 & 0.969 \\
\hline & 10 & 10 & 1.25 & 6.00 & $<0.075$ & 15.518 & 7.77 & 0.980 \\
\hline & 10 & 10 & 2.50 & 2.00 & $<0.075$ & 5.263 & 19.72 & 0.929 \\
\hline & 10 & 10 & 3.75 & 2.00 & $<0.075$ & 7.221 & 15.36 & 0.944 \\
\hline
\end{tabular}

From the results presented in Table 4, it can be realized that the values of $R^{2}$ range from 0.911 to 0.993 for Vpum and 0.886 to 0.969 for VSco. The high values of $R^{2}$ designate the applicability of the Adams-Bohart model for describing the entire sorption mechanisms of fluoride onto VPum and VSco under a continuous fixed-bed flow process.

In a similar fashion with the Thomas model, the comparison of the non-linear plots of the experimental and calculated breakthrough curve, based on the Adams-Bohart model, are generally in good agreement for VPum (a) and VSco (b) at different particle sizes (Figure S4), influent solution $\mathrm{pH}$ (Figure S5), and influent flow rate (Figure S6) respectively. Only minor disparities were noticed at lower $\mathrm{pH}(2.00)$ and particle sizes of $0.075-0.425 \mathrm{~mm}$ and $<0.075 \mathrm{~mm}$ for VPum and VSco, respectively. As seen in Table 4 , the values of the kinetic constants were affected by the influent flow rate and increased with increasing flow rate. This presented that external mass transfer in the entire fluoride adsorption mechanisms in the fixed-bed column dominates the overall system kinetics $[57,60]$. In general, both the Adams-Bohart and the Thomas models could predict very well the entire region of the breakthrough curves for the fluoride-VSco and fluoride-VPum systems. In addition, both the Adams-Bohart model (Equation (19)) and the Thomas model (Equation (18)) are mathematically the same and, therefore, gave similar fit quality.

\subsection{Comparison of Different Adsorbents on Fluoride Removal}

A comparison has been made between volcanic rocks (VPum and VSco) used in this study and previously reported adsorbents for fluoride removal in a fixed-bed column system. The results for some adsorbents are presented in Table 5. 
Table 5. Comparison of other adsorbents with VPum and VSco.

\begin{tabular}{|c|c|c|c|c|c|c|}
\hline Adsorbents & $\begin{array}{l}\text { Surface Area } \\
\qquad\left(\mathrm{m}^{2} \mathrm{~g}^{-1}\right)\end{array}$ & $\begin{array}{l}\text { Bed Depth } \\
(\mathrm{cm})\end{array}$ & $\begin{array}{l}\text { Fluoride in } \\
\left(\mathrm{mgL}^{-1}\right)\end{array}$ & $\begin{array}{l}\text { Adsorption } \\
\text { Capacity } \\
\left(\mathrm{mg} \mathrm{F}^{-} \mathrm{g}^{-1}\right)\end{array}$ & $\begin{array}{c}\text { Adsorption } \\
\text { Capacity per Surface } \\
\text { Area }\left(\mathrm{mg} \cdot \mathrm{m}^{-2}\right)\end{array}$ & References \\
\hline \multirow{2}{*}{$\begin{array}{l}\text { Cement paste } \\
\text { aluminum modified } \\
\text { iron oxide }\end{array}$} & $\mathrm{NA}^{*}$ & 20 & 15 & 0.149 & - & [61] \\
\hline & NA & 10.5 & 4 & 0.139 & - & [62] \\
\hline $\begin{array}{c}\text { Acid-treated } \\
\text { bentonite }(\mathrm{GHB})\end{array}$ & 24.5 & 28 & 2.85 & 0.169 & 0.0069 & [63] \\
\hline $\begin{array}{c}\mathrm{MnO}_{2} \text {-coated } \\
\text { Tamarind Fruit Shell }\end{array}$ & NA & 6 & 2 & 0.883 & - & [64] \\
\hline kanuma mud & 144.01 & 10 & 20 & 1.560 & 0.0108 & [49] \\
\hline $\begin{array}{l}\text { Activated alumina } \\
\text { (Grade OA-25) }\end{array}$ & 250 & 10 & 5 & 0.74 & 0.0029 & [65] \\
\hline VPum & 3.5 & 10 & 10 & 0.110 & 0.0314 & This study \\
\hline VSco & 2.49 & 10 & 10 & 0.022 & 0.0088 & This study \\
\hline
\end{tabular}

NA*: Not available.

As can be seen from these results in Table 5, the natural VPum used is comparable to cement paste and aluminum modified iron oxide in terms of defluoridation capacity. Values of adsorption capacity per unit surface area are, however, higher for VPum than those of acid-treated bentonite (GHB), kanuma mud, and activated alumina; and higher for VSco than acid-treated bentonite (GHB) and activated alumina (Grade OA-25) (Table 5). Both adsorbents are available in abundance in all parts of the world and are readily available in approximately 1/3 of Ethiopia's total area and are, hence, favored adsorption materials because of very low supply costs. The adsorbents used are primarily part of the natural environment. However, to improve the specific surface area and hence the defluoridation capacity, surface modification of the natural volcanic rocks may be appropriate.

\section{Materials and Methods}

\subsection{Materials}

In this study, rock samples were collected from volcanic cones (VPum: $8^{\circ} 10^{\prime} \mathrm{N} 39^{\circ} 50^{\prime} \mathrm{E}$; VSco: $8^{\circ} 33^{\prime} \mathrm{N} 39^{\circ} 16^{\prime} \mathrm{E}$ ) of the Main Rift Valley area of Oromia Regional State, East Showa Zone, Ethiopia, around 50-100 km East of Addis Ababa. The rocks are readily available in approximately $1 / 3$ of the country's total area and are, thus, a preferred adsorption material because of very low supply costs $[29,48,66]$.

\subsection{Preparations of Adsorbents}

The rock samples (VPum and VSco) were washed repeatedly with deionized water until all water-soluble compounds and dust were removed, and thereafter dried at $55{ }^{\circ} \mathrm{C}$ for $48 \mathrm{~h}[30,67]$. After cooling samples down to room temperature, they were crushed with a mortar and sieved using different mesh sizes: silt $(<0.075 \mathrm{~mm})$, fine sand $(0.075-0.425 \mathrm{~mm})$, and medium sand $(0.425-2.00 \mathrm{~mm})[28,68]$. All prepared samples were packed in air-tight plastic bags and stored at a cool and dry place for further use.

\subsection{Preparations of Adsorbate}

All glassware and bottles were thoroughly washed and rinsed with deionized water before usage. Chemicals used were analytical grade reagents and a fluoride stock solution (1000 mg/L) was prepared freshly by dissolving $2.21 \mathrm{~g}$ of anhydrous NaF (Merck KGaA, Darmstadt, Germany) in $1000 \mathrm{~mL}$ of deionized water. The synthetic fluoride solution of desired concentrations was made by diluting the stock solution. $0.1 \mathrm{M}$ of $\mathrm{NaOH}$ and/or $0.1 \mathrm{M} \mathrm{HCl}$ solutions were used to adjust the $\mathrm{pH}$ values of the fluoride solution utilized in the column experimental experiments. 


\subsection{Adsorbent Characterizations}

\subsubsection{Crystalline Structures}

The crystalline structures of the adsorbents were analyzed by an X-ray diffractometer (XRD-7000, Drawell, Shanghai, China) with $\mathrm{Cu} \mathrm{K \alpha}$ as a radiation source (1.54056 $)$ generated at $30 \mathrm{kV}$ and $25 \mathrm{~mA}$ instrument. The diffractograms were gained with a step width of $2 \theta$ and a scan rate of $0.04^{\circ} / \mathrm{min}$.

\subsubsection{Chemical Composition}

The elemental composition of the adsorbents was analyzed using inductively coupled plasma-optical emission spectroscopy (ICP-OES). X-ray fluorescence (XRF) spectroscopy was used to obtain information on the oxide contents of the adsorbents.

\subsubsection{Fourier Transform Infrared (FTIR) Analysis}

FTIR spectra of the samples were run on $\mathrm{KBr}$ pellets. The spectra were recorded over a range of 5000 to $400 \mathrm{~cm}^{-1}$ at a resolution of $0.1 \mathrm{~cm}^{-1}$ in a PerkinElmer spectrometer (UNSW Sydney, Australia) using a lithium tantalite $\left(\mathrm{LiTaO}_{3}\right)$ detector.

\subsubsection{Scanning Electron Microscope (SEM) Analysis}

A scanning electron microscope (SEM) (JCM-6000plus, Version 0.2, Peabody, MA, USA), operated at $15 \mathrm{kV}$, was used to determine the morphologies of VPum and VSco. The characteristics of the adsorbents were compared.

\subsubsection{Determination of $\mathrm{pH}$ and Point of Zero Charges $\left(\mathrm{pH}_{\mathrm{PZC}}\right)$}

The $\mathrm{pH}$ of the adsorbents was determined using a $\mathrm{pH}$ meter in a 1:10 adsorbent/water ratio as per the standard method [6]. The $\mathrm{pH}$ at the point of zero charges $\left(\mathrm{pH}_{\mathrm{PZC}}\right)$ of the adsorbents was examined based on the standard method. For this effect, $250 \mathrm{~mL}$ of $0.01 \mathrm{M}$ $\mathrm{NaCl}$ solution as an electrolyte was positioned in a vessel, thermostated at $298 \mathrm{~K}$, and $\mathrm{N}_{2}$ was bubbled through the solution to stabilize the $\mathrm{pH}$ by preventing the dissolving of $\mathrm{CO}_{2}$ from the air. In 6 Erlenmeyer flasks, $25 \mathrm{~mL}$ of the electrolyte was introduced and the $\mathrm{pH}$ was adjusted to the required value $(2.00,4.00,6.00,8.00,10.00$, and 12.00$)$ by adding $0.1 \mathrm{M} \mathrm{NaOH}$ or $0.1 \mathrm{M} \mathrm{HCl}$. The same procedure and method were performed for blank electrolyte solution $(0.01 \mathrm{M} \mathrm{NaCl})$. In each beaker, $0.25 \mathrm{~g}$ of the rock samples were added and shaken for $48 \mathrm{~h}$. The suspension was subsequently filtrated and the final $\mathrm{pH}$ was determined. The point of zero charges $\left(\mathrm{pH}_{\mathrm{PZC}}\right)$ was found at the intersection point by plotting the initial $\mathrm{pH}$ versus the final $\mathrm{pH}$.

\subsubsection{BET Analysis}

The specific surface area $\left(S_{B E T}\right)$ of the adsorbents was measured using a nitrogen gas adsorption-desorption technique at 77k using surface analyzer equipment (Micrometrics/ Gemini-2372). The samples were degassed at $300{ }^{\circ} \mathrm{C}$ under vacuum for at least $6 \mathrm{~h}$ before analysis. The Brunauer-Emmett-Teller (BET) equation was used to obtain a specific surface area $\left(S_{B E T}\right)$. The $S_{B E T}$ values of the two adsorbents (VPum and VSco) are compared.

\subsection{Column Adsorption Experimental Set-Up and Procedures}

Continuous fixed-bed column adsorption studies were carried out to assess the dynamic behavior of fluoride removal by using VPum and VSco. Continuous flow adsorption experiments were conducted in a small-scale cylindrical column of $8.1 \mathrm{~cm}$ internal diameter and $10 \mathrm{~cm}$ height with an empty bed volume of $515 \mathrm{~cm}^{3}$. The column was filled with a weighted amount of adsorbent of different particle sizes (silt: $<0.075 \mathrm{~mm}$, fine sand: $0.075-0.425 \mathrm{~mm}$, and medium sand: $0.425-2.00 \mathrm{~mm}$ ). The same particle size was used if controlling parameters such as $\mathrm{pH}$ and flow rate were tested. The bed was conditioned with deionized water ( $\mathrm{pH}$ : 7.00-7.30) for $12 \mathrm{~h}$ (overnight) to ensure a closely packed adsorbent and to avoid the potential occurrence of voids, channeling, or cracking, which can significantly affect the performance of the column. 
A synthetic fluoride solution with a concentration of $10 \mathrm{mg} / \mathrm{L}$ was pumped to a packed bed column in up-flow mode to avoid channeling caused by gravity. The influent volumetric flow rate varied between experiments but was held constant in a given experiment using an adjustable peristaltic pump (MS-REGLO, Labortechnik-Analytic, Zürich, Switzerland). The experiments were conducted at room temperature $\left(25 \pm 2{ }^{\circ} \mathrm{C}\right)$. The effluent column sample was collected using an automatic fraction collector (RFI, MA-RON $\mathrm{GmbH}$, Germany). The constant flow rate was verified by collecting and quantifying the effluent solution at regular time intervals. The column operation was stopped when the concentrations of the fluoride in the effluent exceeded $90 \%$ of its initial concentrations. Ion chromatography (930 Compact IC Flex, Metrohm, Switzerland) was used to quantify fluoride concentrations. The instrument uses $3.2 \mathrm{mmol} / \mathrm{L} \mathrm{Na}_{2} \mathrm{CO}_{3} / 1.0 \mathrm{mmol} / \mathrm{L} \mathrm{NaHCO}$ as eluent, Metrosep A Supp 5-150/4.0 column, and a standard conductivity detector to measure the conductivity of the effluent solutions. The fluoride concentration was measured in the calibration range of $0.2-200 \mathrm{mg} / \mathrm{L}$, contains inline dilution, inline dialysis, eluent degasser, $\mathrm{CO}_{2}$ suppressor, and chemical suppressor. Suppression in IC maximizes the detection sensitivity of fluoride ions while reducing the background conductivity of the eluent.

The maximum tolerable breakthrough concentration $\left(C_{b}\right)$ was $1.5 \mathrm{mg} / \mathrm{L}(15 \%$ of the influent initial concentration of $10 \mathrm{mg} / \mathrm{L}$ ), which is recommended by WHO [4] as a maximum acceptable level for drinking water.

The effect of experimental parameters such as particles size (silt: $<0.075 \mathrm{~mm}$, fine sand: $0.075-0.425 \mathrm{~mm}$, and medium sand: $0.075-0.425 \mathrm{~mm})$, influent solution $\mathrm{pH}(2.00,4.00$, and $6.00)$, and influent volumetric flow rate $(1.25,2.50$, and $3.75 \mathrm{~mL} / \mathrm{min})$ on breakthrough behavior and amount of fluoride removed were examined.

\subsection{Modeling and Analysis of Fixed-Bed Column Data}

A fixed-bed column adsorption performance is well described through the breakthrough curve concept [53]. The time of solute breakthrough and the shape of the breakthrough curve are important indicators for the operational adsorption processes; the breakthrough curve is directly linked to the viability and economics of the adsorption process $[54,69]$. The breakthrough patterns and according parameters are dependent on the operating conditions of the fixed-bed column such as adsorbent particle size, influent flow rate, and $\mathrm{pH}$ of the influent solution. Nevertheless, the $\mathrm{pH}$ value may not influence the breakthrough curve in a situation such as when using strongly basic anion exchangers. The primary and significant attribute is the sorbent selectivity to the pollutant, as well as the dynamic exchange capacity and full dynamic capacity of the column [70]. To investigate the performance of the column and to scale-up, the determination of breakthrough parameters is crucial. The breakthrough curves expressed in terms of the ratio of effluent to influent adsorbate concentration $\left(C_{t} / C_{o}\right)$ as a function of time or effluent volume for a given height of the bed reflects the absorbed fluoride from the solution. Time equivalent to stoichiometric capacity (exhaustion time) and time equivalent to usable capacity (breakthrough time) is shown in Equations (4) and (5), respectively [54,59].

$$
\begin{gathered}
\mathrm{t}_{\mathrm{e}}=\int_{\mathrm{t}=0}^{\mathrm{t}=\mathrm{t}_{\text {total }}}\left(1-\frac{\mathrm{C}_{\mathrm{t}}}{\mathrm{C}_{\mathrm{o}}}\right) \mathrm{dt} \\
\mathrm{t}_{\mathrm{b}}=\int_{\mathrm{t}=0}^{\mathrm{t}_{\mathrm{b}}}\left(1-\frac{\mathrm{C}_{\mathrm{b}}}{\mathrm{C}_{\mathrm{o}}}\right) \mathrm{dt}
\end{gathered}
$$

where $t_{e}$ is exhaustion time $(\mathrm{min}), t_{b}$ is the breakthrough time $(\min )$ at which $C_{t}=C_{b}$ $(\mathrm{mg} / \mathrm{L})$ (for the present system, $\mathrm{C}_{\mathrm{b}}=1.5 \mathrm{mg} / \mathrm{L}$ ).

The total value of fluoride adsorbed $\left(\mathrm{q}_{\mathrm{total}}: \mathrm{mg}\right)$ from the column for a given feed concentration and the flow rate was obtained from the area (A) under the breakthrough 
curve by integrating the adsorbed fluoride concentration $C_{a d}\left(C_{a d}=C_{o}-C_{t}\right)\left(m g L^{-1}\right)$ versus $\mathrm{t}(\mathrm{min})$ and can be obtained from Equation (6) [55,71].

$$
\mathrm{q}_{\text {total }}=\frac{\mathrm{QA}}{1000}=\frac{\mathrm{Q}}{1000} \int_{\mathrm{t}=0}^{\mathrm{t}=\mathrm{t}_{\text {total }}} \mathrm{C}_{\mathrm{ad}} \mathrm{dt}
$$

where $t_{\text {total }}$, and $Q$ are the total flow time until saturation of the bed (min), and volumetric flow rate $(\mathrm{mL} / \mathrm{min})$, respectively.

Equilibrium fluoride uptake ( $\mathrm{q}_{\mathrm{e}} \mathrm{mg} \mathrm{kg}^{-1}$ ) (maximum capacity of the column) in the column is calculated by Equation $(7)$ as the total amount of fluoride adsorbed $\left(q_{\text {total }}\right)$ per kilogram of dry adsorbent mass (m) at the end of the total flow time [71].

$$
\mathrm{q}_{\mathrm{eq}}=\frac{\mathrm{q}_{\text {total }}}{\mathrm{m}}
$$

The effluent volume $\left(\mathrm{V}_{\mathrm{e}}\right)$ and treated effluent volume or breakthrough volume $\left(\mathrm{V}_{\mathrm{b}}\right)$ of solution can be found from Equations (8) and (9), respectively.

$$
\begin{aligned}
& \mathrm{V}_{\mathrm{e}}=\mathrm{Qt}_{\mathrm{e}} \\
& \mathrm{V}_{\mathrm{b}}=\mathrm{Qt}_{\mathrm{b}}
\end{aligned}
$$

where, $\mathrm{V}_{\mathrm{e}}$ is the total effluent volume at exhaustion time $(\mathrm{mL}), \mathrm{V}_{\mathrm{b}}$, total effluent volume at the breakthrough time $(\mathrm{mL}), \mathrm{Q}$ is the volumetric flow rate $(\mathrm{mL} / \mathrm{min}), \mathrm{t}_{\mathrm{e}}$ and $\mathrm{t}_{\mathrm{b}}$ are exhaustion and breakthrough time (min), respectively.

The Mass Transfer Zone (MTZ) or unused bed length $\left(\mathrm{H}_{\mathrm{UNB}}\right)$ can be obtained from Equation (10) [54,59].

$$
\mathrm{MTZ}=\mathrm{H}_{\mathrm{T}}\left(\frac{\mathrm{t}_{\mathrm{e}}-\mathrm{t}_{\mathrm{b}}}{\mathrm{t}_{\mathrm{e}}}\right)
$$

where $\mathrm{H}_{\mathrm{T}}$ is total bed height $(\mathrm{cm}), \mathrm{t}_{\mathrm{e}}(\mathrm{min})$ is exhaustion time, and $\mathrm{t}_{\mathrm{b}}$ is breakthrough time ( $\mathrm{min})$.

The Empty Bed Contact Time (EBCT), which measures the critical depth and the contact time between the solid phase adsorbent and the liquid phase, can be obtained from Equation (11).

$$
\mathrm{EBCT}=\frac{\mathrm{V}_{\mathrm{B}}}{\mathrm{Q}}
$$

where $V_{B}$ is the volume of a fixed bed $(\mathrm{mL})$ and $Q$ is the flow rate $(\mathrm{mL} / \mathrm{min})$.

The bulk density $\left(\rho_{\mathrm{b}}: \mathrm{gm} . \mathrm{cm}^{-3}\right)$, which measures the adsorbent compaction status, and the particle density $\left(\rho_{\mathrm{p}}: \mathrm{gm} \cdot \mathrm{cm}^{-3}\right)$ of the adsorbent can be obtained from Equations (12) and (13), respectively [72].

$$
\begin{gathered}
\rho_{\mathrm{b}}=\frac{\mathrm{m}_{\mathrm{ads}}}{\mathrm{V}_{\mathrm{t}}} \\
\rho_{\mathrm{p}}=\frac{\mathrm{m}_{\mathrm{ads}}}{\mathrm{V}_{\mathrm{t}}-\mathrm{V}_{\mathrm{v}}}
\end{gathered}
$$

where $m_{a d s}$ is the dry mass of adsorbent $(\mathrm{mg})$, and $V_{t}$ is the bulk volume $\left(\mathrm{cm}^{3}\right)$ which includes the volume of adsorbent $\left(\mathrm{V}_{\mathrm{B}}: \mathrm{cm}^{3}\right)$ and the pore space between the adsorbent particles or void volume $\left(\mathrm{V}_{\mathrm{v}}: \mathrm{cm}^{3}\right)$.

The void volume $\left(\mathrm{V}_{\mathrm{v}}: \mathrm{cm}^{3}\right)$ of the adsorbent can be found from Equation (14) [72].

$$
\mathrm{V}_{\mathrm{v}}=\frac{\mathrm{W}_{\text {Sat }}-\mathrm{W}_{\mathrm{dry}}}{\rho_{\mathrm{w}}}
$$

where $\mathrm{W}_{\mathrm{dry}}$ is the weight of dry adsorbent $(\mathrm{g}), \mathrm{W}_{\text {sat }}$ is the weight of saturated adsorbent $(\mathrm{g})$, and $\rho_{\mathrm{w}}$ is the density of water $\left(\mathrm{g} \mathrm{cm}^{-3}\right)$. 
The total porosity of the adsorbent $\left(\varepsilon_{\mathrm{b}}\right)$ can be obtained from Equation (15) [72].

$$
\varepsilon_{\mathrm{b}}=1-\frac{\rho_{b}}{\rho_{p}}
$$

The filter (superficial) velocity $\left(\mathrm{V}_{\mathrm{f}}: \mathrm{cm} \mathrm{min}{ }^{-1}\right)$ and effective (interstitial) velocity $\left(\mathrm{V}_{\mathrm{I}}: \mathrm{cm} \mathrm{min}^{-1}\right)$ can be found from Equations (16) and (17), respectively [72].

$$
\begin{gathered}
\mathrm{V}_{\mathrm{f}}=\frac{\mathrm{Q}}{\mathrm{A}} \\
\mathrm{V}_{\mathrm{I}}=\frac{\mathrm{Q}}{\mathrm{A} \times \varepsilon_{\mathrm{b}}}
\end{gathered}
$$

where $\mathrm{A}$ is the cross-sectional area of the fixed-bed $\left(\mathrm{cm}^{2}\right)$ and $\mathrm{Q}$ is the flow rate $\left(\mathrm{cm}^{3} \mathrm{~min}^{-1}\right)$.

\subsection{Fixed-Bed Column Breakthrough Curve Modeling}

The successive operation of a small scale column towards industrial applications can be well elucidated with the help of some models. Various models have been reported for predicting the breakthrough performance in fixed-bed adsorption [57,73]. In this study, the two most important and widely used mathematical models, the Thomas model and AdamsBohart model, have been applied to the column experimental data for describing the dynamic behavior of fluoride adsorption using VPum and VSco in a fixed-bed column filter.

\subsubsection{Thomas Model}

The Thomas model [74] is one of the most extensively employed kinetic models to predict fixed-bed column performance. In addition to the prediction of the breakthrough curve for the effluent, the model can be used to determine the maximum uptake of adsorbate and adsorption rate constant [74]. The non-linear form of the Thomas model can be described as follows Equation (18), [75].

$$
\frac{\mathrm{C}_{\mathrm{t}}}{\mathrm{C}_{\mathrm{o}}}=\frac{1}{1+\exp \left[\mathrm{K}_{\mathrm{T}} \mathrm{q}_{\mathrm{o}} \frac{\mathrm{m}}{\mathrm{Q}}-\mathrm{K}_{\mathrm{T}} \mathrm{C}_{\mathrm{o}} \mathrm{t}\right]}
$$

where $C_{o}(m g / L)$ is the initial solute concentration, $C_{t}(m g / L)$ is the solute concentration at the time, $\mathrm{t}, \mathrm{Q}(\mathrm{L} / \mathrm{min})$ is the volumetric flow rate, $\mathrm{q}_{\mathrm{o}}(\mathrm{mg} / \mathrm{kg})$ is the maximum solid-phase concentration of solute (maximum column adsorption capacity), $\mathrm{K}_{\mathrm{T}}$ is the Thomas rate constant $(\mathrm{L} / \mathrm{min} \mathrm{mg})$, and $\mathrm{m}(\mathrm{kg})$ is the packed dry mass of the adsorbent in a fixed-bed.

\subsubsection{Adams-Bohart Model}

The Adams-Bohart model [76] was developed for the analysis of the dynamics of fixed-bed based on the assumption that the adsorption rate is proportional to both the residual adsorbent and adsorbate concentration. The nonlinear form of the Adams-Bohart model (Equation (19)) [77], was used for the prediction of breakthrough curves and model parameters.

$$
\frac{\mathrm{C}_{\mathrm{t}}}{\mathrm{C}_{\mathrm{o}}}=\frac{1}{1+\exp \left[\mathrm{K}_{\mathrm{AB}} \mathrm{N}_{\mathrm{o}} \frac{\mathrm{Z}}{v}-\mathrm{K}_{\mathrm{AB}} \mathrm{C}_{\mathrm{o}} \mathrm{t}\right]}
$$

Where $\mathrm{K}_{\mathrm{AB}}(\mathrm{L} / \mathrm{mg} \mathrm{min})$ is the kinetic constant, $v(\mathrm{~mL} / \mathrm{min})$ is the linear flow rate, $\mathrm{Z}$ $(\mathrm{cm})$ is a column bed depth, and $\mathrm{N}_{\mathrm{O}}(\mathrm{mg} / \mathrm{L})$ is the saturation concentration (adsorption capacity of the adsorbent per unit volume of the bed), and time $t$ ( $\mathrm{min}$ ) ranges from the start to fluoride breakthrough point. The linear flow rate was determined by Equation (20).

$$
v=\frac{\mathrm{Q}}{\mathrm{A}}
$$


where $\mathrm{Q}\left(\mathrm{cm}^{3} / \mathrm{min}\right)$ is the volumetric flow rate, and $\mathrm{A}\left(\mathrm{cm}^{2}\right)$ is the cross-sectional area of the bed $[60,62,78]$.

\section{Conclusions}

In this study, the removal of fluoride from aqueous solutions was examined in a continuous fixed-bed adsorption column system using VPum and VSco. The characterizations investigations were performed using XRD, SEM, FTIR, BET, XRF, and ICP-OES equipment to reveal the mechanisms of adsorption and the suitability of the adsorbents for fluoride removal. The $\mathrm{pH}_{\mathrm{PZC}}$ is 6.98 for VSco and 6.85 for VPum. The effects of process parameters such as adsorbent particle size, influent $\mathrm{pH}$, and influent volumetric flow-rate on the performance of the adsorption process in a column were evaluated. The maximum removal capacity of $110 \mathrm{mg} / \mathrm{kg}$ for VPum and $22 \mathrm{mg} / \mathrm{kg}$ for VSco were achieved at a particle size of $0.075-0.425 \mathrm{~mm}$ and $<0.075 \mathrm{~mm}$, respectively, at lower solution $\mathrm{pH}(2.00)$ and flow rate $(1.25 \mathrm{~mL} / \mathrm{min})$. The increase in adsorbent particle size, solution $\mathrm{pH}$, and flow rate decreases the breakthrough and saturation time of the column bed and, consequently, lowers the amount of fluoride removal by VSco. The breakthrough and exhaustion time on VPum was high at a particle size of $0.075-0.425 \mathrm{~mm}$, at lower solution $\mathrm{pH}$ and flow rate similar to that of VSco. Thus, in order to attain optimum performance, suitable experimental parameters are significant for the operation of the adsorption column. The Thomas and Adams-Bohart models were applied to the experimental data to estimate the breakthrough curves and to determine fixed-bed column kinetic parameters. Both the Adam-Bohart and the Thomas models could predict very well the entire region of the breakthrough curves for the fluoride-VSco and fluoride-VPum system. The results show that VPum and VSco could be used in a fixed-bed adsorption column for the removal of excess fluoride from water. The supply cost of the two adsorbents is very low; nevertheless, an overall cost analysis of the purification system is very important as it has implications for the feasibility (technical and economic) of the adsorption method. Additional testing of the adsorbents including representative samples test for possible compositional, mineralogical, and textural changes in time due to weathering, leaching test, competitive ions effects, and regeneration options is required to confirm that the defluoridation of groundwater employing volcanic rocks is a safe and sustainable method.

Supplementary Materials: Table S1: Elemental composition and oxides content of VPum and VSco, Figure S1: Experimental (exp.) and simulated (cal.; Thomas model) breakthrough curves of fluoride at different particle sizes for (a) VPum and (b) VSco (pH 2.00; $\mathrm{C}_{\mathrm{O}}: 10 \mathrm{mg} / \mathrm{L} ; \mathrm{Q}_{\mathrm{O}}: 1.25 \mathrm{~mL} / \mathrm{min}$; bed depth $10 \mathrm{~cm}$ ), Figure S2: Experimental and simulated (Thomas model) breakthrough curves of fluoride at different $\mathrm{pH}$ for (a) VPum: 0.075-0.425 mm (b) VSco: $<0.075 \mathrm{~mm}$ (CO: $10 \mathrm{mg} / \mathrm{L}$; QO: $1.25 \mathrm{~mL} / \mathrm{min}$; bed depth $10 \mathrm{~cm}$ ), Figure S3: Experimental and simulated (Thomas model) breakthrough curves of fluoride at different influent flow rate for (a) VPum: 0.075-0.425 mm and (b) VSco: $<0.075 \mathrm{~mm}\left(\mathrm{pH} 2.00 ; \mathrm{C}_{\mathrm{O}}: 10 \mathrm{mg} / \mathrm{L}\right.$; bed depth $10 \mathrm{~cm}$ ), Figure S4: Experimental (exp.) and simulated (cal.; Adams-Bohart model) breakthrough curves of fluoride at different particle sizes for (a) VPum and (b) VSco (pH 2.00; $\mathrm{C}_{\mathrm{O}}: 10 \mathrm{mg} / \mathrm{L}$; $\mathrm{Q}_{\mathrm{O}}: 1.25 \mathrm{~mL} / \mathrm{min}$; bed depth $10 \mathrm{~cm}$ ), Figure S5: Experimental and simulated (Adams-Bohart model) breakthrough curves of fluoride at different pH for (a) VPum: 0.075-0.425 mm and (b) VSco: $<0.075 \mathrm{~mm}\left(\mathrm{C}_{\mathrm{O}}: 10 \mathrm{mg} / \mathrm{L} ; \mathrm{Q}_{\mathrm{O}}: 1.25 \mathrm{~mL} / \mathrm{min}\right.$; bed depth $10 \mathrm{~cm}$ ), Figure S6: Experimental and simulated (Adams-Bohart model) breakthrough curves of fluoride at different flow rate for (a) VPum: $0.075-0.425 \mathrm{~mm}$ and (b) VSco: $<0.075 \mathrm{~mm}$ (pH 2.00; $\mathrm{C}_{\mathrm{O}}: 10 \mathrm{mg} / \mathrm{L}$; bed depth $10 \mathrm{~cm}$ ).

Author Contributions: W.S.G. prepared the adsorbents, designed and conducted the adsorption experiments, analyzed the data, and prepared the manuscript; E.A. supervised the research work, updated and reviewed the manuscript; B.L. supervised the research work, reviewed and edited the article. All authors have read and agreed to the published version of the manuscript.

Funding: This research received no external funding.

Institutional Review Board Statement: Not applicable.

Informed Consent Statement: Not applicable. 
Data Availability Statement: The data used in this study can be available from the authors on reasonable request.

Acknowledgments: The first author is greatly thankful to the German Academic Exchange Service (DAAD) for providing the scholarship during the study.

Conflicts of Interest: The authors declare no conflict of interest.

Sample Availability: Samples of the adsorbents (VPum and VSco) are available from the authors.

\section{References}

1. Kumari, U.; Mishra, A.; Siddiqi, H.; Meikap, B.C. Effective Defluoridation of Industrial Wastewater by Using Acid Modified Alumina in Fixed-Bed Adsorption Column: Experimental and Breakthrough Curves Analysis. J. Clean. Prod. 2021, 279, 123645:1-123645:17. [CrossRef]

2. Kumari, U.; Behera, S.K.; Siddiqi, H.; Meikap, B.C. Facile Method to Synthesize Efficient Adsorbent from Alumina by Nitric Acid Activation: Batch Scale Defluoridation, Kinetics, Isotherm Studies and Implementation on Industrial Wastewater Treatment. J. Hazard. Mater. 2020, 381, 120917. [CrossRef]

3. Ye, Y.; Yang, J.; Jiang, W.; Kang, J.; Hu, Y.; Ngo, H.H.; Guo, W.; Liu, Y. Fluoride Removal from Water Using a Magnesia-Pullulan Composite in a Continuous Fixed-Bed Column. J. Environ. Manag. 2018, 206, 929-937. [CrossRef] [PubMed]

4. WHO World Health Organization. Guidelines for Drinking-Water Quality, 4th ed.; WHO World Health Organization: Geneva, Swizerland, 2011; ISBN 978-92-4-154815-1.

5. Rango, T.; Vengosh, A.; Jeuland, M.; Whitford, G.M.; Tekle-haimanot, R. Biomarkers of Chronic Fluoride Exposure in Groundwater in a Highly Exposed Population. Sci. Total Environ. 2017, 596-597, 1-11. [CrossRef] [PubMed]

6. Fufa, F.; Alemayehu, E.; Lennartz, B. Defluoridation of Groundwater Using Termite Mound. Water. Air. Soil Pollut. 2013, 224, 1552:1-1552:15. [CrossRef]

7. Rango, T.; Bianchini, G.; Beccaluva, L.; Tassinari, R. Geochemistry and Water Quality Assessment of Central Main Ethiopian Rift Natural Waters with Emphasis on Source and Occurrence of Fluoride and Arsenic. J. Afr. Earth Sci. 2010, 57, 479-491. [CrossRef]

8. Demelash, H.; Beyene, A.; Abebe, Z.; Melese, A. Fluoride Concentration in Ground Water and Prevalence of Dental Fluorosis in Ethiopian Rift Valley: Systematic Review and Meta-Analysis. BMC Public Health 2019, 19, 1298. [CrossRef]

9. Cai, J.; Zhang, Y.; Pan, B.; Zhang, W.; Lv, L.; Zhang, Q. Efficient Defluoridation of Water Using Reusable Nanocrystalline Layered Double Hydroxides Impregnated Polystyrene Anion Exchanger. Water Res. 2016, 102, 109-116. [CrossRef]

10. CSAE Central Statistical Agency of Ethiopia. Drinking Water Quality in Ethiopia-Results from the 2016 Ethiopia Socioeconomic Survey; CSAE Central Statistical Agency of Ethiopia: Addis Ababa, Ethiopia, 2017.

11. Kut, K.M.K.; Sarswat, A.; Srivastava, A.; Pittman, C.U., Jr.; Mohan, D. A Review of Fluoride in African Groundwater and Local Remediation Methods. Groundw. Sustain. Dev. 2016, 2-3, 190-212. [CrossRef]

12. Shen, J.; Schäfer, A.I. Factors Affecting Fluoride and Natural Organic Matter (NOM) Removal from Natural Waters in Tanzania by Nano Filtration/Reverse Osmosis. Sci. Total Environ. 2015, 527-528, 520-529. [CrossRef]

13. Smedley, P.L.; Nkotagu, H.; Pelig-Ba, K.; MacDonald, A.M.; TylerWhittle, R.; Whitehead, E.J.; Kinniburgh, D.G. Fluoride in Groundwater from High-Fluoride Areas of Ghana and Tanzania; Commissioned Report CR/02/316; British Geological Survey Groundwater Systems and Water Quality Programme: Nottingham, UK, 2002.

14. Mohan, S.; Kumar, V.; Singh, D.K.; Hasan, S.H. Synthesis and Characterization of RGO/ZrO2 Nanocomposite for Enhanced Removal of Fluoride from Water: Kinetics, Isotherm, and Thermodynamic Modeling and Its Adsorption Mechanism. RSC Adv. 2016, 6, 87523-87538. [CrossRef]

15. Araga, R.; Kali, S.; Sharma, C.S. Coconut-Shell-Derived Carbon/Carbon Nanotube Composite for Fluoride Adsorption from Aqueous Solution. Clean Soil Air Water 2019, 47, 1-9. [CrossRef]

16. Waghmare, S.S.; Arfin, T. Fluoride Removal from Water by Various Techniques: Review. Int. J. Innov. Sci. Eng. Technol. 2015, 2, 560-571.

17. Manna, S.; Saha, P.; Roy, D.; Adhikari, B.; Das, P. Fixed Bed Column Study for Water Defluoridation Using Neem Oil-Phenolic Resin Treated Plant Bio-Sorbent. J. Environ. Manag. 2018, 212, 424-432. [CrossRef]

18. Gill, T.; Tiwari, S.; Kumar, P.A. A Review on Feasibility of Conventional Fluoride Removal Techniques in Urban Areas. Int. J. Environ. Res. Dev. 2014, 4, 179-182.

19. Liu, J.; Yue, X.; Lu, X.; Guo, Y. Uptake Fluoride from Water by Starch Stabilized Layered Double Hydroxides. Water 2018, 10, 745. [CrossRef]

20. Yadav, K.K.; Gupta, N.; Kumar, V.; Khan, S.A.; Kumar, A. A Review of Emerging Adsorbents and Current Demand for Defluoridation of Water: Bright Future in Water Sustainability. Environ. Int. 2018, 111, 80-108. [CrossRef]

21. Su, T.; Song, Y.; Lan, X.; Gao, W. Optimization for Removal e Ffi Ciency of Fl Uoride Using La ( III )-Al ( III )-Activated Carbon Modi Fi Ed by Chemical Route. Green Process. Synth. 2020, 9, 405-415. [CrossRef]

22. Nehra, S.; Raghav, S.; Kumar, D. Biomaterial Functionalized Cerium Nanocomposite for Removal of Fluoride Using Central Composite Design Optimization Study. Environ. Pollut. 2020, 113773:1-113773:32. [CrossRef] 
23. Abu Bakar, A.H.; Abdullah, L.C.; Mohd Zahri, N.A.; Alkhatib, M. Column Efficiency of Fluoride Removal Using Quaternized Palm Kernel Shell (QPKS). Int. J. Chem. Eng. 2019, 5743590:1-5743590:13. [CrossRef]

24. Kennedy, A.M.; Arias-Paic, M. Fixed-Bed Adsorption Comparisons of Bone Char and Activated Alumina for the Removal of Fluoride from Drinking Water. J. Environ. Eng. 2020, 146, 04019099. [CrossRef]

25. Alkurdi, S.S.A.; Al-Juboori, R.A.; Bundschuh, J.; Hamawand, I. Bone Char as a Green Sorbent for Removing Health Threatening Fluoride from Drinking Water. Environ. Int. 2019, 127, 704-719. [CrossRef] [PubMed]

26. Rajkumar, S.; Murugesh, S.; Sivasankar, V.; Darchen, A.; Msagati, T.A.M.; Chaabane, T. Low-Cost Fluoride Adsorbents Prepared from a Renewable Biowaste: Syntheses, Characterization and Modeling Studies. Arab. J. Chem. 2019, 12, 3004-3017. [CrossRef]

27. Ghanbarian, M.; Ghanbarian, M.; Mahvi, A.H.; Tabatabaie, T. Enhanced Fluoride Removal over MgFe2O4-Chitosan-CaAl Nanohybrid: Response Surface Optimization, Kinetic and Isotherm Study. Int. J. Biol. Macromol. 2020, 148, 574-590. [CrossRef]

28. Alemayehu, E.; Lennartz, B. Virgin Volcanic Rocks: Kinetics and Equilibrium Studies for the Adsorption of Cadmium from Water. J. Hazard. Mater. 2009, 169, 395-401. [CrossRef] [PubMed]

29. Aregu, M.B.; Asfaw, S.L.; Khan, M.M. Identification of Two Low-Cost and Locally Available Filter Media (Pumice and Scoria) for Removal of Hazardous Pollutants from Tannery Wastewater. Environ. Syst. Res. 2018, 7, 10:1-10:14. [CrossRef]

30. Asere, T.G.; Mincke, S.; De Clercq, J.; Verbeken, K.; Tessema, D.A.; Fufa, F.; Stevens, C.V.; Du Laing, G. Removal of Arsenic (V) from Aqueous Solutions Using Chitosan-Red Scoria and Chitosan-Pumice Blends. Int. J. Environ. Res. Public Health 2017, 14, 895. [CrossRef]

31. Asere, T.G.; Verbeken, K.; Tessema, D.A.; Fufa, F.; Stevens, C.V.; Du Laing, G. Adsorption of As(III) versus As(V) from Aqueous Solutions by Cerium-Loaded Volcanic Rocks. Environ. Sci. Pollut. Res. 2017, 24, 20446-20458. [CrossRef]

32. Birhane, M.; Abebe, A.; Alemayehu, E.; Mengistie, E. Efficiency of Locally Available Filter Media on Fluoride and Phosphate Removal for Household Water Treatment System. Chin. J. Popul. Resour. Environ. 2014, 12, 110-115. [CrossRef]

33. Viswanathan, N.; Meenakshi, S. Enriched Fluoride Sorption Using Alumina/Chitosan Composite. J. Hazard. Mater. 2010, 178, 226-232. [CrossRef] [PubMed]

34. Monash, P.; Pugazhenthi, G. Removal of Crystal Violet Dye from Aqueous Solution Using Calcined and Uncalcined Mixed Clay Adsorbents. Sep. Sci. Technol. 2010, 45, 94-104. [CrossRef]

35. Patel, H. Fixed-Bed Column Adsorption Study: A Comprehensive Review. Appl. Water Sci. 2019, 9, 45:1-45:17. [CrossRef]

36. US EPA United States Environmental Agency. Control of Organic Substances in Water and Wastewater; Document No.: U.S. EPA-600/8-83-011; U.S. Environmental Protection Agency: Washington, DC, USA, 1983.

37. Rowe, M.C.; Brewer, B.J. AMORPH: A Statistical Program for Characterizing Amorphous Materials by X-Ray Diffraction 1. Comput. Geosci. 2018, 120, 24-31. [CrossRef]

38. Li, X.; Yang, W.; Zou, Q.; Zuo, Y. Investigation on Microstructure, Compostion, and Cytocompatibility of Natural Pumice for Potential Biomedical Application. Tissue Eng. Part C 2010, 16, 427-434. [CrossRef]

39. Sepehr, M.N.; Amrane, A.; Karimaian, K.A.; Zarrabi, M.; Ghaffari, H.R. Potential of Waste Pumice and Surface Modified Pumice for Hexavalent Chromium Removal: Characterization, Equilibrium, Thermodynamic and Kinetic Study. J. Taiwan Inst. Chem. Eng. 2014, 45, 635-647. [CrossRef]

40. Pirsaheb, M.; Mohammadi, H.; Sharafi, K.; Asadi, A. Fluoride and Nitrate Adsorption from Water by Fe(III)-Doped Scoria: Optimizing Using Response Surface Modeling, Kinetic and Equilibrium Study. Water Sci. Technol. Water Supply 2017, 18, 1117-1132. [CrossRef]

41. Djobo, J.N.Y.; Tchadjié, L.N.; Tchakoute, H.K.; Kenne, B.B.D.; Elimbi, A. Synthesis of Geopolymer Composites from a Mixture of Volcanic Scoria and Metakaolin. J. Asian Ceram. Socities 2014, 2, 387-398. [CrossRef]

42. Panias, D.; Giannopoulou, I.P.; Perraki, T. Effect of Synthesis Parameters on the Mechanical Properties of Fly Ash-Based Geopolymers. Colloids Surfaces A Physicochem. Eng. Asp. 2007, 301, 246-254. [CrossRef]

43. Asgari, G.; Roshani, B.; Ghanizadeh, G. The Investigation of Kinetic and Isotherm of Fluoride Adsorption onto Functionalize Pumice Stone. J. Hazard. Mater. 2012, 217-218, 123-132. [CrossRef]

44. Moradi, M.; Mansouri, A.M.; Azizi, N.; Amini, J. Adsorptive Removal of Phenol from Aqueous Solutions by Copper (Cu)Modified Scoria Powder: Process Modeling and Kinetic Evaluation. Desalin. Water Treat. 2015, 57, 1-15. [CrossRef]

45. Souza, R.F.; Brandão, P.R.G.; Paulo, J.B.A. Effect of Chemical Composition on the Zeta -Potential of Chromite. Miner. Eng. 2012, 36-38, 65-74. [CrossRef]

46. Ayoob, S.; Gupta, A.K. Performance Evaluation of Alumina Cement Granules in Removing Fluoride from Natural and Synthetic Waters. Chem. Eng. J. 2009, 150, 485-491. [CrossRef]

47. Salifu, A.; Petrusevski, B.; Ghebremichael, K.; Modestus, L.; Buamah, R.; Aubry, C.; Amy, G.L. Aluminum (Hydr) Oxide Coated Pumice for Fluoride Removal from Drinking Water: Synthesis, Equilibrium, Kinetics and Mechanism. Chem. Eng. J. 2013, 228, 63-74. [CrossRef]

48. Alemayehu, E.; Thiele-Bruhn, S.; Lennartz, B. Adsorption Behaviour of Cr (VI) onto Macro and Micro-Vesicular Volcanic Rocks from Water. Sep. Purif. Technol. 2011, 78, 55-61. [CrossRef]

49. Chen, N.; Zhang, Z.; Feng, C.; Li, M.; Chen, R.; Sugiura, N. Investigations on the Batch and Fixed-Bed Column Performance of Fluoride Adsorption by Kanuma Mud. Desalination 2011, 268, 76-82. [CrossRef]

50. Alemayehu, E.; Lennartz, B. Adsorptive Removal of Nickel from Water Using Volcanic Rocks. Appl. Geochem. 2010, 25, 1596-1602. [CrossRef] 
51. Obijole, O.A.; Gitari, M.W.; Ndungu, P.G. Mechanochemically Activated Aluminosilicate Clay Soils and Their Application for Defluoridation and Pathogen Removal from Groundwater. Int. J. Environ. Res. Public Health 2019, 16, 654. [CrossRef]

52. Sepehr, M.N.; Zarrabi, M.; Kazemian, H.; Amrane, A.; Yaghmaian, K.; Ghaffari, H.R. Removal of Hardness Agents, Calcium and Magnesium, by Natural and Alkaline Modified Pumice Stones in Single and Binary Systems. Appl. Surf. Sci. 2013, 274, 295-305. [CrossRef]

53. Aksu, Z.; Çağatay, S.S.; Gönen, F. Continuous Fixed Bed Biosorption of Reactive Dyes by Dried Rhizopus Arrhizus: Determination of Column Capacity. J. Hazard. Mater. 2007, 143, 362-371. [CrossRef]

54. Golie, W.M.; Upadhyayula, S. Continuous Fixed-Bed Column Study for the Removal of Nitrate from Water Using Chitosan/Alumina Composite. J. Water Process Eng. 2016, 12, 58-65. [CrossRef]

55. Paudyal, H.; Pangeni, B.; Inoue, K.; Kawakita, H.; Ohto, K.; Alam, S. Adsorptive Removal of Fluoride from Aqueous Medium Using a Fixed Bed Column Packed with Zr (IV) Loaded Dried Orange Juice Residue. Bioresour. Technol. 2013, 146, 713-720. [CrossRef] [PubMed]

56. Ghorai, S.; Pant, K.K. Equilibrium, Kinetics and Breakthrough Studies for Adsorption of Fluoride on Activated Alumina. Sep. Purif. Technol. 2005, 42, 265-271. [CrossRef]

57. Salifu, A. Laboratory-Scale Column Filter Studies for Fluoride Removal with Aluminium (Hydr) Oxide Coated Pumice, Regeneration and Disposal. In Fluoride Removal from Groundwater by Adsorption Technology: The Occurrence, Adsorbent Synthesis, Regeneration and Disposal; CRC Press/Balkema: Leiden, The Netherlands, 2017; pp. 127-129. ISBN 9780815392071.

58. Han, R.; Wang, Y.; Yu, W.; Zou, W.; Shi, J.; Liu, H. Biosorption of Methylene Blue from Aqueous Solution by Rice Husk in a Fixed-Bed Column. J. Hazard. Mater. 2007, 141, 713-718. [CrossRef]

59. Yagub, M.T.; Sen, T.K.; Afroze, S.; Ang, H.M. Fixed-Bed Dynamic Column Adsorption Study of Methylene Blue (MB) onto Pine Cone. Desalin. Water Treat. 2015, 55, 1026-1039. [CrossRef]

60. Quintelas, C.; Pereira, R.; Kaplan, E.; Tavares, T. Removal of Ni (II) from Aqueous Solutions by an Arthrobacter Viscosus Biofilm Supported on Zeolite: From Laboratory to Pilot Scale. Bioresour. Technol. 2013, 142, 368-374. [CrossRef]

61. Kang, W.H.; Kim, E.I.; Park, J.Y. Fluoride Removal Capacity of Cement Paste. Desalination 2007, 202, 38-44. [CrossRef]

62. García-sánchez, J.J.; Solache-ríos, M.; Martínez-miranda, V.; Morelos, C.S. Removal of Fluoride Ions from Drinking Water and Fluoride Solutions by Aluminum Modified Iron Oxides in a Column System. J. Colloid Interface Sci. 2013, 407, 410-415. [CrossRef]

63. Ma, Y.; Shi, F.; Zheng, X.; Ma, J.; Gao, C. Removal of Fluoride from Aqueous Solution Using Granular Acid-Treated Bentonite (GHB): Batch and Column Studies. J. Hazard. Mater. 2011, 185, 1073-1080. [CrossRef] [PubMed]

64. Sivasankar, V.; Ramachandramoorthy, T.; Chandramohan, A. Fluoride Removal from Water Using Activated and MnO2-Coated Tamarind Fruit (Tamarindus Indica) Shell: Batch and Column Studies. J. Hazard. Mater. 2010, 177, 719-729. [CrossRef] [PubMed]

65. Ghorai, S.; Pant, K.K. Investigations on the Column Performance of Fluoride Adsorption by Activated Alumina in a Fixed-Bed. Chem. Eng. J. 2004, 98, 165-173. [CrossRef]

66. Alemayehu, E.; Melak, F.; Sharma, S.K.; Van Der Bruggen, B.; Lennartz, B. Use of Porous Volcanic Rocks for the Adsorptive Removal of Copper. Water Environ. J. 2017, 31, 4-11. [CrossRef]

67. Kwon, J.-S.; Yun, S.-T.; Lee, J.-H.; Kim, S.-O.; Jo, H.Y. Removal of Divalent Heavy Metals (Cd, Cu, Pb, and Zn) and Arsenic (III) from Aqueous Solutions Using Scoria: Kinetics and Equilibria of Sorption. J. Hazard. Mater. 2010, 174, 307-313. [CrossRef]

68. Liu, C.; Evett, J.B. Soil Properties-Testing, Measurament, and Evalution; Banta Book Company: Upper Saddle River, NJ, USA, 2003; ISBN 0-13-093005-9.

69. Chen, I.-P.; Kan, C.-C.; Futalan, C.; Calagui, M.J.; Lin, S.-S.; Tsai, W.-C.; Wan, M.-W. Batch and Fixed Bed Studies: Removal of Copper (II) Using Chitosan-Coated Kaolinite Beads from Aqueous Solution. Sustain. Environ. Res. 2015, $25,73-81$.

70. De Gennaro, B.; Aprea, P.; Liguori, B.; Galzerano, B.; Peluso, A.; Caputo, D. Zeolite-Rich Composite Materials for Environmental Remediation: Arsenic Removal from Water. Appl. Sci. 2020, 10, 6939. [CrossRef]

71. Chen, S.; Yue, Q.; Gao, B.; Li, Q.; Xu, X.; Fu, K. Adsorption of Hexavalent Chromium from Aqueous Solution by Modified Corn Stalk: A Fixed-Bed Column Study. Bioresour. Technol. 2012, 113, 114-120. [CrossRef]

72. Worch, E. Adsorption Technology in Water Treatment: Fundamentals, Processes, and Modeling; Walter de Gruyter and Co.KG: Berlin, Germany, 2012; ISBN 9783110240221.

73. Mohan, S.; Singh, D.K.; Kumar, V.; Hasan, S.H. Modelling of Fixed Bed Column Containing Graphene Oxide Decorated by MgO Nanocubes as Adsorbent for Lead ( II ) Removal from Water. J. Water Process Eng. 2017, 17, 216-228. [CrossRef]

74. Thomas, H.C. Heterogeneous Ion Exchange in a Flowing System. J. Am. Chem. Soc. 1944, 66, 1664-1666. [CrossRef]

75. Singh, T.P.; Ghosh, S.; Cb, M. Adsorption of Fluoride from Industrial Wastewater in Fixed Bed Column Using Java Plum (Syzygium Cumini). Asian J. Pharm. Clin. Res. 2016, 9. [CrossRef]

76. Bohart, G.S.; Adams, E.Q. Some Aspects of the Behavior of Charcoal with Respect to Chlorine. J. Am. Chem. Society 1920, 42, 523-544. [CrossRef]

77. Chu, K.H. Breakthrough Curve Analysis by Simplistic Models of Fixed Bed Adsorption: In Defense of the Century-Old BohartAdams Model. Chem. Eng. J. 2020, 380, 122513:1-122513:8. [CrossRef]

78. Han, R.; Zou, L.; Zhao, X.; Xu, Y.; Xu, F.; Li, Y.; Wang, Y. Characterization and Properties of Iron Oxide-Coated Zeolite as Adsorbent for Removal of Copper (II) from Solution in Fixed Bed Column. Chem. Eng. J. 2009, 149, 123-131. [CrossRef] 